\title{
Tight regulation of wingless-type signaling in the articular cartilage - subchondral bone biomechanical unit: transcriptomics in Frzb- knockout mice
}

\author{
Liesbet Lodewyckx ${ }^{1}$, Frédéric Cailotto ${ }^{1}$, Sarah Thysen ${ }^{1}$, Frank P Luyten ${ }^{1,2}$ and Rik J Lories ${ }^{1,2^{*}}$
}

\begin{abstract}
Introduction: The aim of this research was to study molecular changes in the articular cartilage and subchondral bone of the tibial plateau from mice deficient in frizzled-related protein (Frzb) compared to wild-type mice by transcriptome analysis.
\end{abstract}

Methods: Gene-expression analysis of the articular cartilage and subchondral bone of three wild-type and three $\mathrm{Frzb}^{-1-}$ mice was performed by microarray. Data from three wild-type and two Frzb $b^{-1}$ samples could be used for pathway analysis of differentially expressed genes and were explored with PANTHER, DAVID and GSEA bioinformatics tools. Activation of the wingless-type (WNT) pathway was analysed using Western blot. The effects of Frzb gain and loss of function on chondrogenesis and cell proliferation was examined using ATDC5 micromasses and mouse ribcage chondrocytes.

Results: Extracellular matrix-associated integrin and cadherin pathways, as well as WNT pathway genes were upregulated in $\mathrm{Frzb}^{-1}$ samples. Several WNT receptors, target genes and other antagonists were up-regulated, but no difference in active $\beta$-catenin was found. Analysis of ATDC5 cell micro-masses overexpressing FRZB indicated an up-regulation of aggrecan and Col2a1, and down-regulation of molecules related to damage and repair in cartilage, Col3ar and Col5a1. Silencing of Frzb resulted in down-regulation of aggrecan and Col2a1. Pathways associated with cell cycle were down-regulated in this transcriptome analysis. Ribcage chondrocytes derived from Frzb $b^{-1-}$ mice showed decreased proliferation compared to wild-type cells.

Conclusions: Our analysis provides evidence for tight regulation of WNT signalling, shifts in extracellular matrix components and effects on cell proliferation and differentiation in the articular cartilage - subchondral bone unit in $\mathrm{Frzb}^{-1-}$ mice. These data further support an important role for FRZB in joint homeostasis and highlight the complex biology of WNT signaling in the joint.

\section{Introduction}

Homeostasis of articular cartilage and subchondral bone is essential for maintenance of joint function which is critically dependent on the balance between anabolic and catabolic signaling pathways $[1,2]$. It requires maintenance of the stable phenotype that characterises the articular cartilage, sustained extracellular matrix (ECM)

\footnotetext{
* Correspondence: Rik.Lories@med.kuleuven.be

'Laboratory for Skeletal Development and Joint Disorders, Department of Development and Regeneration, KU Leuven, Belgium

Full list of author information is available at the end of the article
}

synthesis, efficient breakdown and clearance of damaged macromolecules and dead cells, as well as functional and molecular adaptations to mechanic loads. Loss of homeostasis results in gradual deterioration of cartilage quality and thickening of the subchondral bone, progressively leading to osteoarthritis (OA).

The wingless-type (WNT) signaling pathway plays an important role in cartilage, bone and joint development and has been associated with postnatal joint homeostasis and disease [3,4]. WNTs are a group of at least 19 structurally related secreted glycoproteins that activate

\section{Ciomed Central}

(c) 2012 Lodewyckx et al.; licensee BioMed Central Ltd. This is an open access article distributed under the terms of the Creative Commons Attribution License (http://creativecommons.org/licenses/by/2.0), which permits unrestricted use, distribution, and reproduction in any medium, provided the original work is properly cited. 
different intracellular cascades [5]. Among these, canonical WNT signaling involving $\beta$-catenin has been studied best. In the absence of a WNT-Frizzled low density lipoprotein receptor-related protein-5/6 co-receptor interaction (WNT-FZD-LRP5/6), $\beta$-catenin is caught in a molecular destruction complex, phosphorylated and degraded by the proteasome. Upon WNT-receptor interaction, the destruction complex is disassembled, $\beta$ catenin accumulates in the cell, translocates to the nucleus and associates with transcription factors of the $\mathrm{T}$-cell factor/lymphoid enhancer factor (TCF/LEF) family. Alternatively, non-canonical WNT signaling can alter calcium balances in the cell or activate protein kinases $[5,6]$.

WNTs, their extracellular antagonists, such as the secreted frizzled-related proteins (SFRPs), co-receptor inhibitors, such as the dickkopfs (DKKs), and $\beta$-catenin have been studied in animal models of OA and OA patients [7-13]. Current data suggest that canonical WNT signaling plays an essential role in joint and bone formation $[14,15]$ and in the maintenance of the articular cartilage phenotype, which is characterised by extended cell survival and absence of differentiation towards hypertrophy [16]. Cartilage-specific inhibition of $\beta$-catenin results in an OA-like phenotype with chondrocyte apoptosis [8]. Cartilage-specific overexpression of a constitutively active form of $\beta$-catenin also results in an OA-like phenotype, but here the disease is characterised by loss of the chondrocyte's differentiation status and expression of hypertrophic markers [9].

Frizzled-related protein (Frzb, also known as SFRP3) is a WNT antagonist originally identified from a chondrogenic extract of articular cartilage [17] and plays a role in skeletal development $[17,18]$. Polymorphisms in FRZB have been associated with OA [3]. We previously developed mice that are genetically deficient in Frzb. These mice do not develop spontaneous arthritis but are more susceptible to OA in induced models [7]. This observation has been linked to increased WNT signaling and $M m p 3$ expression in the articular cartilage. The cortical bone in these mice is thicker and the bones show an enhanced anabolic response upon mechanical loading compared to wild-type mice. In this study, we used $\mathrm{Frzb}^{-/-}$mice to further evaluate how the absence of a WNT antagonist affects molecular homeostasis in the articular cartilage and subchondral bone.

\section{Materials and methods}

\section{Mice and tissue sampling}

$\mathrm{Frzb}^{-1-}$ mice were generated in our research group [7] and back-crossed into the C57Bl/6J background for over 10 generations. Genotypes were determined as described [7]. Six-week-old male $\mathrm{Frzb}^{-1-}$ and wild-type mice were sacrificed by cervical dislocation. The articular cartilage and subchondral bone from the tibial plateau of the knee joint of the hind limb was carefully dissected in one piece at the growth plate region using micro-dissection forceps, a procedure easy to perform at this age when the growth plate is not yet closed. The tissues were immediately snap frozen in liquid nitrogen and stored at $-80^{\circ} \mathrm{C}$ until further processing or used for histology. Animal procedures were approved by the Ethical Committee for Animal Research, KULeuven.

\section{Microarray hybridization and data acquisition}

Per microarray, articular cartilage and subchondral bone from a single joint were used. Samples were homogenised using the Fastprep-24 tissue-homogeniser (MP Biomedicals, Solon, OH, USA) in lysing matrix A tubes and RLT lysis buffer (RNeasy Fibrous Tissue kit (Qiagen, Chatsworth, CA, USA)). Samples were kept under pre-cooled conditions using the CryoPrep Adaptor. RNA was isolated with the RNeasy Fibrous Tissue kit (Qiagen) with proteinase $\mathrm{K}$ and deoxyribonuclease (DNaseI) treatment. RNA concentration and purity were assessed with a NanoDrop Spectrophotometer (NanoDrop Technologies, Centreville, DE, USA) and integrity was determined using RNA nanochips and the Agilent 2100 Bio-analyzer (Agilent Technologies, Diegem, Belgium). Only non-degraded RNA without impurities (RNA integrity number > 7.7), was considered for microarray analysis.

Transcriptional profiles of three $\mathrm{Frzb}^{-/-}$and three wildtype samples were analyzed by the VIB Microarray Facility [19]. Per sample, $2 \mu \mathrm{g}$ of total RNA spiked with bacterial RNA transcript positive controls (Affymetrix, Santa Clara, CA, USA) was converted to double stranded cDNA. Subsequently, the sample was converted and amplified to antisense cRNA and labeled with biotin. A mixture of purified and fragmented biotinylated cRNA and hybridisation controls (Affymetrix) was hybridised on Affymetrix GeneChip Mouse Genome 430-2.0 arrays followed by staining and washing in a GeneChip fluidics station 450 (Affymetrix). To assess the raw probe signal intensities, chips were scanned using a GeneChip scanner 3000 (Affymetrix). Microarray data have been deposited in the Gene Expression Omnibus (GEO) [20] and are accessible through Gene Expression Omnibus accession number GSE33656.

\section{Western blot analysis}

Proteins were isolated from the dissected articular cartilage and subchondral bone pieces using cell extraction buffer (Invitrogen, Merelbeke, Belgium) supplemented with $1 \mathrm{mM}$ phenylmethanesulfonyl (Sigma-Aldrich, Bornem, Belgium) and 5\% protease inhibitor cocktail (Sigma-Aldrich) using the Fastprep-24 tissue homogeniser (MP Biomedicals). A total of $20 \mu \mathrm{g}$ of each sample 
was denatured and separated on a 4 to $12 \%$ polyacrylamide Bis-Tris gel (Invitrogen) by electrophoresis using NuPage MES SDS Running buffer (Invitrogen). Proteins were transferred to a PVDF (polyvinylidene difluoride) membrane (Millipore, Brussels, Belgium). Non-specific binding sites were blocked using 5\% blottoB (Santa Cruz Biotechnology, Santa Cruz, CA, USA) in Tris-buffered saline with $0.1 \%$ Tween (TBS/T) for one hour at room temperature. Blots were probed overnight at $4^{\circ} \mathrm{C}$ with the following antibodies: $1 / 500$ dephospho- $\beta$-catenin (CTNNB1) sheep antibody (Genway Biotech, San Diego, CA, USA), 1/1,000 phospho-Smad1(Ser463/465)/Smad5 (Ser463/465)/Smad8(Ser426/428) rabbit antibody (Cell Signaling Technology, Danvers, MA, USA), 1/500 antiSFRP1 rabbit antibody (Abcam, Cambridge, UK), 1/500 mouse DKK2 affinity purified polyclonal goat antibody, 1/1,000 mouse SFRP2 affinity purified polyclonal goat antibody (both from R\&D Systems, Minneapolis, MN, USA) or $1 / 4,000$ anti-GAPDH mouse monoclonal $6 \mathrm{C} 5$ (Ambion, Applied Biosystems) in 5\% bovine serum albumin in TBS/T with $0.02 \%$ sodiumazide. Horseradish peroxidase-conjugated donkey anti-sheep $(1 / 5,000)$, mouse anti-rabbit (light chain specific) $(1 / 5,000)$, donkey antigoat $(1 / 5,000)$ and goat anti-mouse $(1 / 50,000)$ polyclonal antibodies (Jackson ImmunoResearch Laboratories, West Grove, PA, USA) in 5\% blottoB in TBS/T were used as secondary antibodies. Blots were visualised using Western Lightning Chemiluminescent Substrate (Perkin Elmer Life and Analytical Sciences, Inc., Waltham, MA, USA) for dephospho- $\beta$-catenin, DKK2, SFRP2, SFRP1 and GAPDH or SuperSignal West Femto Maximum Sensitivity Substrate (Pierce, Thermo Scientific, Rockford, IL, USA) for phosphorylated Smad. Densitometry analysis was performed with ImageJ Software (NIH Image, National Institutes of Health, Bethesda, MD, USA [21]).

\section{Cell culture experiments}

ATDC5 cells were cultured in maintenance medium (1:1 Dulbecco's modified Eagle's medium (DMEM):Ham's F12 mix (Gibco Life Technologies, Gent, Belgium), 1\% antibiotic-antimycotic (AB) (Gibco), 5\% fetal bovine serum (FBS) (Gibco) containing $10 \mu \mathrm{g} / \mathrm{ml}$ human transferrin and $30 \mathrm{mM}$ sodiumselenite (Sigma-Aldrich) and maintained in a humidified atmosphere of $5 \% \mathrm{CO}_{2}$ and $95 \% \mathrm{O}_{2}$ at $37^{\circ} \mathrm{C}$.

In $F R Z B$ overexpression experiments, ATDC5 cells were transfected with control pcDNA3.1+ (Invitrogen) or the pcDNA3.1-full length FRZB construct (pfrzb [17]) using lipid-based agent Fugene HD (Roche Diagnostics, Vilvoorde, Belgium). After 24 hours, selection with $1 \mathrm{mg} / \mathrm{ml}$ geneticin (Gibco) was initiated. Selection medium was renewed every day for 14 days. Antibiotic resistant cells were dilution-cloned.
In Frzb knock-down experiments, ATDC5 cells were transfected with control pGIPZ-non-silencing shRNAmir (Open Biosystems, Thermo Scientific IT IS Open Biosystems, Thermo Scientific, Lafayette, CO, USA) or with a pGIPZ-shRNAmir directed against Frzb (Open Biosystems) using lipo-polymeric agent Arrest-In (Open Biosystems). After 24 hours, selection with $0.5 \mu \mathrm{g} / \mathrm{ml}$ puromycin was initiated. Selection medium was renewed every day for seven days. Antibiotic resistant cells were dilution-cloned.

Stably-transfected ATDC5 cells were grown in micromasses to undergo chondrogenesis. Three drops cell suspension $\left(2 \times 10^{5}\right.$ cells $)$ were placed in a single well of a standard 12-well culture plate. The cells were allowed to adhere for two hours at $37^{\circ} \mathrm{C}$, then $1 \mathrm{ml}$ maintenance medium was added to each well. Geneticin or puromycin pressure was maintained during chondrogenesis.

Micro-masses were cultured in the maintenance medium containing an ITS premix $(10 \mu \mathrm{g} / \mathrm{ml}$ insulin, $5 \mu \mathrm{g} /$ $\mathrm{ml}$ human transferrin and $30 \mathrm{mM}$ sodiumselenite) (Gibco) and $5 \mu \mathrm{g} / \mathrm{ml}$ human transferrin for two weeks. The mineralization phase was induced using $\alpha$-MEM medium (Gibco) containing 5\% fetal bovine serum (Gibco), ITS premix, $5 \mu \mathrm{g} / \mathrm{ml}$ human transferrin and 7 $\mathrm{mM}$ beta-glycerolphosphate (Sigma-Aldrich) from Day 14 until Day 21. Each condition was performed in triplicate. Total RNA from micro-masses was isolated after 7 , 14 or 21 days in culture using the Nucleospin RNA II kit (Macherey-Nagel, Düren, Germany).

Protein extraction of the micro-masses stably overexpressing $F R Z B$ or controls after seven days was performed using cell extraction buffer supplemented with 1 $\mathrm{mM}$ phenylmethanesulfonyl and 5\% protease inhibitor cocktail, followed by quantification using the Pierce BCA Protein Assay kit (Thermo Scientific).

Some ATDC5 micro-masses were fixed in 95\% icecold methanol for staining. For Picrosirius Red, micromasses were stained for one hour in Picrosirius Red (0.1\% Direct Red 80 (Sigma-Aldrich) in a saturated aqueous solution of picric acid), washed three times with $0.5 \%$ acetic acid in water and air-dried. For Safranin O, micro-masses were stained for one hour in Safranin O ( $1 \%$ alcoholic solution (Klinipath, Olen, Belgium)), washed three times with water and air-dried. Quantification of the staining was performed by dissolving the micro-masses with $1 \mathrm{M} \mathrm{NaOH}$ (for Picrosirius Red) or $6 \mathrm{M}$ Guanidine- $\mathrm{HCl}$ (for Safranin O) (both from SigmaAldrich) and by measuring the absorbance at 540 and $512 \mathrm{~nm}$ respectively with the Infinite M200 (Tecan, Männedorf, Switzerland).

\section{CDNA synthesis and Quantitative Real-Time PCR}

Complementary DNA was synthesised from $1 \mu \mathrm{g}$ of RNA isolated from tibia articular cartilage and 
subchondral bone pieces or ATDC5 cell micro-masses using the RevertAid $\mathrm{H}$ minus First Strand cDNA synthesis kit (Fermentas GmbH, St-Leon-Rot, Germany). TaqMan gene expression assays (Applied Biosystems, Carlsbad, CA, USA) or the SYBRgreen master mix system (Fermentas) were used to verify differential expression of Frzb (Mm00441378_m1), Sfrp1 (Mm00489161_m1), Sfrp2 (Mm0485986_m1), Dkk2 (Mm00445025_m1), aggrecan (forward 5'-GCTGCAGTGATCTCAGAAGAAG-3', reverse 3'-GATGGTGAGGGAAGACCCTA-5'), Col3a1 (forward 5'TTATTCTCCCCAATTCGACTCA-3', reverse 3'AGATCCAGGATGTCCAGAAGAA-5'), Colsa1 (forward 5'-CGGATGTTGCCTACCGAGT, reverse 3'ACGGTTGTCAGGATGGAGAA-5') and Col2a1 (Mm01309565_m1) (forward 5'-CCAGGATGCCCGAAAATTAG-3', reverse 3'-TTCTCCCTTGTCACCACGAT-5'). For TaqMan assays analysis was performed using the PerfeCTa qPCR FastMix UNG (Quanta Biosciences, Gaithersburg, MD, USA) using the following conditions: 1 minute at $95^{\circ} \mathrm{C}, 40$ cycles of 3 seconds of denaturation at $95^{\circ} \mathrm{C}$, followed by 20 seconds of annealing-extension at $60^{\circ} \mathrm{C}$. All experiments were performed in duplicate. For SYBRgreen, quantitative analysis was performed as follows: 10 minutes at $95^{\circ} \mathrm{C}$, 40 cycles of 15 seconds of denaturation at $95^{\circ} \mathrm{C}$, followed by 60 seconds of annealing-extension at $60^{\circ} \mathrm{C}$. Melting curve analysis was performed to ensure amplification of a specific product. The Corbett Rotor-Gene 6000 (Corbett Research, Westburg, Leusden, The Netherlands) was used for both systems. Results are expressed using the comparative threshold method [22] and were normalised to housekeeping gene Hprt (hypoxanthine guanine phosphoribosyl transferase) (Mm00446968_m1 or forward 5'-TGCTGACCTGCTGGATTACA-3', reverse 3'-TATGTCCCCCGTTGACTGAT-5').

\section{Mouse rib chondrocyte isolation and proliferation analysis}

Rib and sternum chondrocytes were isolated from three six-week-old wild-type and three $\mathrm{Frzb}^{-/-}$mice, as described with minor modifications [23]. The sternum was longitudinally cut, followed by complete removal of the ventral part of the ribcage. The ribcage was washed three times in Dulbecco's phosphate buffered saline (DPBS) (Lonza, Verviers, Belgium) with 1\% AB (Gibco). Soft tissues were digested in $3 \mathrm{mg} / \mathrm{ml}$ collagenase D (Roche Diagnostics) in medium (DMEM, 1\% AB and 1\% sodium pyruvate (Invitrogen)) for $1 \mathrm{~h}$ standing upright in a collection tube in humidified atmosphere of $5 \%$ $\mathrm{CO}_{2}$ and $95 \% \mathrm{O}_{2}$ at $37^{\circ} \mathrm{C}$, followed by rotation for a further $1.5 \mathrm{~h}$. Soft tissues were carefully removed, followed by further digestion in fresh $3 \mathrm{mg} / \mathrm{ml}$ collagenase
$\mathrm{D}$ in medium when the soft tissues kept adhering. After washing twice in DPBS with $1 \% \mathrm{AB}$, cartilage was digested using $1 \mathrm{mg} / \mathrm{ml}$ collagenase $\mathrm{D}$ in medium overnight in a petri dish in the incubator. The medium containing chondrocytes was transferred to a collection tube. The bones were rinsed with complete growth medium (10\% FBS (Gibco)) and this was also transferred to the collection tube. After centrifugation, cells were resuspended in $4 \mathrm{ml}$ complete growth medium, plated on a T25 plate (Greiner Bio-One, Frickenhausen, Germany) and grown until confluent. The medium was changed every two days. For the proliferation assay, chondrocytes from three $\mathrm{Frzb}^{-/-}$and three wild-type mice were plated at different cell densities $(500,2,000$ or 4,000 cells/well) in triplicate on fluorescence compatible 96-well flat bottom plates ( $\mu$ Clear-plate, black, 98well, Greiner Bio-one). Fluorescence was measured $24 \mathrm{~h}$ and 1 week after plating using the CyQuant NF Cell proliferation kit (Molecular Probes, Invitrogen) and the Wallac Victor 1420 Multilabel counter (Perkin Elmer) at an excitation wavelength of $485 \mathrm{~nm}$ and emission of 535 $\mathrm{nm}$. The difference in fluorescence between the two time points ( $24 \mathrm{~h}$ and 1 week) was calculated and considered the amount of proliferation in that time window. A different plate was used for each time point.

\section{Bioinformatics analysis and statistics}

The quality of hybridization and data acquisition was assessed by RNA-degradation plots, histograms of the perfect match values distribution and quality control graphs. Data were pre-processed by removal of the hybridisation, labeling control and absent probe sets, followed by a $\log 2$ transformation and normalisation of the results to obtain the Robust Multiarray Averaging (RMA) algorithm defined expression values and the Microarray Analysis Suite (MAS) 5.0 software detection calls. Significant differences in gene expression were defined using a modified t-test by the limma package from Bioconductor [24] followed by Benjamini-Hochberg multiple testing correction. For further analysis, we used the PANTHER [25], DAVID [26] and GSEA [27] tools [28-33].

PANTHER uses pathways compiled by experts and determines the representation of a specific pathway on the selected gene list by applying a binomial statistic to which we applied an additional false discovery rate (FDR) test. Only pathways that included at least 15 annotated genes were taken into consideration. With DAVID we interrogated representation in KEGG [34] and Biocarta pathways [35]. It uses a modified Fisher's exact test and applies a Benjamini-Hochberg multiple testing correction. The GSEA system uses all data in the microarray analysis in a ranked list and compares a maximal enrichment score to a series of 1,000 random 
permutations resulting in nominal $P$-values and FDR qvalues. For GSEA analysis, the KEGG curated pathway set, the miRNA motif and transcription factor motif gene sets were used applying 1,000 permutations defined by the gene set. A weighed enrichment statistic using log2-ratio of classes was applied. A stringent limit with a nominal $P$-value $<0.001$ and a FDR $q$-value $<0.01$ was applied. In addition, we compiled a list of WNT target genes based on the WNT homepage [36] (see Additional file 1) and used a Yates corrected Chi-square test to compare our selected gene lists with the reference list. Other datasets were analyzed using a Mann-Whitney test for unpaired samples.

In silico promoter analysis of the Col3a1, Colsa1 and Col5a3 genes was performed using the TFSearch [37] and ALIBABA [38] online software, based on the TRANSFAC algorithm. Stringent criteria were applied so that only the responsive elements with a high homology to the consensus sequence matched our search (> 90\%). Additionally, TCF/LEF responsive elements, specific transcription factors associated with WNT signaling, were investigated using the different consensus sequences as previously identified [39].

\section{Result}

\section{Primary analysis of the microarrays}

We were able to dissect the subchondral bone and articular cartilage in one piece (Figure 1A). The heatmap of the RMA expression values from the microarray analysis showed clustering of the transcriptomes into groups formed by the three wild-type and two out of three $\mathrm{Frzb}^{-1-}$ mice, respectively (Figure 1B). The third presumed $F r z b^{-/-}$mouse clustered with the wild-types and was subsequently identified by re-genotyping as a heterozygous animal. This sample was not used in the analysis. A total of 697 probe sets out of 30,590 that had a "present" detection call were significantly up-regulated in the $\mathrm{Frzb}^{-/-}$samples and 1,524 were significantly down-regulated as compared to the wild-type mice (defined by a $P$ value $<0.01$ after Benjamini-Hochberg correction and | $\log 2 \mid$-ratio $>1)$. Cartilage-specific and bone-specific genes were found in the highest percentiles of expressed genes in the microarray analysis, whereas genes specifically related to T cells, B cells and platelets were found in lower percentiles; possibly from RNA originating from the subchondral bone marrow (Figure 1C).

Using the PANTHER resource, 493 mapped genes were identified as up-regulated and 905 mapped genes were identified as down-regulated in $\mathrm{Frzb}^{-1-}$ mice. The 25 genes with the largest fold-difference between $\mathrm{Frzb}^{-/-}$ and wild-type mice are presented in Table 1. A complete list of all regulated genes and fold differences can be found in the additional materials (see Additional file 2).
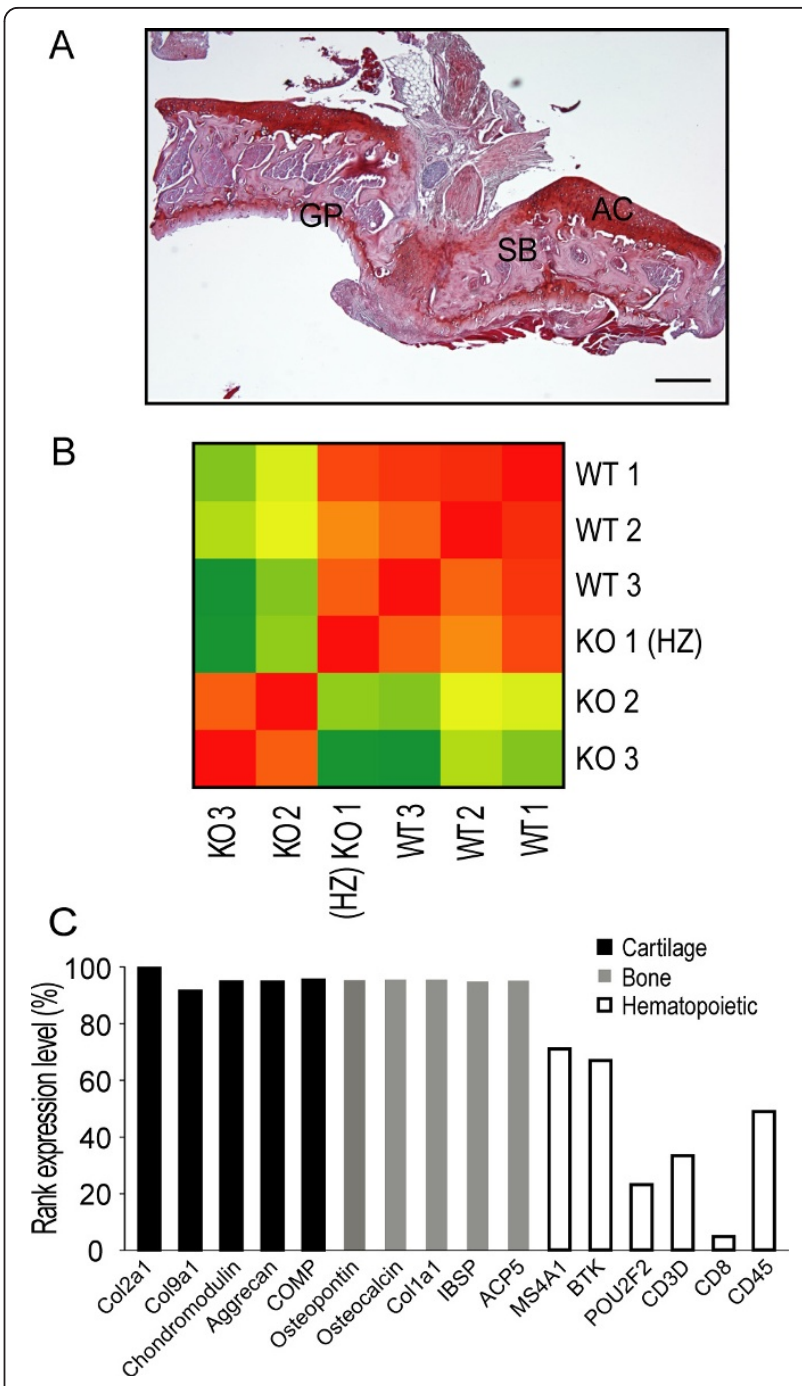

Figure 1 Microarray analysis of cartilage and subchondral bone. (A) Frontal hematoxylin-safranin $O$ stained section of the tibia articular cartilage and subchondral bone isolated from a wildtype C57BI/6 mouse at six weeks of age. Dissected tissues include the articular cartilage (AC), the underlying subchondral bone (SB) containing trabeculae and bone marrow and the upper part of the growth plate (GP). Scale bar $=50 \mu \mathrm{m}$ (B) Heatmap showing the correlation between the Robust Multiarray Averaging (RMA) expression values for all samples. The three wild-type (WT) and one heterozygous frizzled-related protein $\left(\mathrm{Frzb}^{+/-}\right)(\mathrm{HZ})$ mouse cluster apart from the two $\mathrm{Frzb}^{--}(\mathrm{KO})$ mice. Correlations are presented by colors going from green (lowest) to red (highest). (C) Analysis of the representation of genes in the microarray associated with articular cartilage (collagen type 2a1 (Col2a1), collagen type 9a1 (Col9a1), aggrecan, chondromodulin, cartilage oligomeric matrix protein (Comp)), bone (osteopontin, osteocalcin, collagen type 1a1 (Col1a1), bone sialoprotein 2 (Ibsp), tartrate-resistant acid phosphatase type 5 (Acp5)), and hematopoiesis (B-lymphocyte antigen CD20 (Ms4a1), Bcell progenitor kinase $(B t k)$, lymphoid-restricted immunoglobulin octamer-binding protein (Pou2f2), CD3 antigen (CD3), CD8 antigen (CD8), protein tyrosine phosphatase, receptor type C (CD45)). Cartilage- and bone-specific genes were found in the highest percentiles, while $T$ cell, B cell and platelet related genes, were found in lower amounts. 
Table 1 Top 25 differentially up- and down-regulated genes by log fold change (LogFC)

\begin{tabular}{|c|c|c|c|c|c|}
\hline \multicolumn{3}{|c|}{ Up-regulated genes } & \multicolumn{3}{|c|}{ Down-regulated genes } \\
\hline Symbol & Name & LogFC & Symbol & Name & LogFC \\
\hline Dbp & D site albumin promoter binding protein & 3.551 & Olfm4 & olfactomedin 4 & -4.248 \\
\hline Pck1 & phosphoenolpyruvate carboxykinase 1, cytosolic & 2.836 & $\begin{array}{l}\operatorname{lgkv15-} \\
103\end{array}$ & immunoglobulin kappa chain variable 15-103 & -4.238 \\
\hline Rbm45 & RNA binding motif protein 45 & 2.689 & Apol11b & apolipoprotein $L$ 11b & -4.151 \\
\hline Aspn & asporin & 2.464 & Frzb & frizzled-related protein & -3.606 \\
\hline Angpt/7 & angiopoietin-like 7 & 2.461 & Mmp8 & matrix metallopeptidase 8 & -3.531 \\
\hline Htra4 & HtrA serine peptidase 4 & 2.442 & $C d 51$ & CD5 antigen-like & -3.442 \\
\hline Nnat & neuronatin & 2.367 & Slfn1 & schlafen 1 & -3.388 \\
\hline Epha3 & Eph receptor A3 & 2.367 & Apol8 & apolipoprotein L 8 & -3.345 \\
\hline Lrrn4Cl & LRRN4 C-terminal like & 2.355 & Car1 & carbonic anhydrase 1 & -3.338 \\
\hline Angpt/1 & angiopoietin-like 1 & 2.344 & Gypa & glycophorin A & -3.328 \\
\hline Matn4 & matrilin 4 & 2.315 & Spnal & spectrin alpha 1 & -3.294 \\
\hline Olfm/1 & olfactomedin-like 1 & 2.276 & Myb & myeloblastosis oncogene & -3.264 \\
\hline Col14a1 & collagen, type XIV, alpha 1 & 2.260 & Epb4.2 & erythrocyte protein band 4.2 & -3.245 \\
\hline Cdh13 & cadherin 13 & 2.230 & Ceacam10 & $\begin{array}{l}\text { carcinoembryonic antigen-related cell adhesion molecule } \\
10\end{array}$ & -3.218 \\
\hline Col14a1 & collagen, type XIV, alpha 1 & 2.202 & Spna1 & spectrin alpha 1 & -3.175 \\
\hline Sfrp1 & secreted frizzled-related protein 1 & 2.199 & Cd177 & CD177 antigen & -3.173 \\
\hline Pck1 & phosphoenolpyruvate carboxykinase 1, cytosolic & 2.189 & lgj & immunoglobulin joining chain & -3.158 \\
\hline Dkk3 & dickkopf homolog 3 (Xenopus laevis) & 2.166 & Gypa & glycophorin A & -3.156 \\
\hline $\operatorname{Nr} 1 d 2$ & nuclear receptor subfamily 1 , group $D$, member 2 & 2.142 & Rhd & Rh blood group, D antigen & -3.152 \\
\hline Adrb3 & adrenergic receptor, beta 3 & 2.138 & Fam55b & family with sequence similarity 55 , member $B$ & -3.151 \\
\hline Gnas & $\begin{array}{l}\text { guanine nucleotide binding protein, alpha } \\
\text { stimulating }\end{array}$ & 2.132 & Abca13 & ATP-binding cassette, sub-family A ( $A B C 1)$, member 13 & -3.142 \\
\hline Dkk2 & dickkopf homolog 2 (Xenopus laevis) & 2.131 & Mylk3 & myosin light chain kinase 3 & -3.139 \\
\hline Hmen 1 & hemicentin 1 & 2.116 & Ankrd43 & ankyrin repeat domain 43 & -3.135 \\
\hline Gpr1 & G protein-coupled receptor 1 & 2.115 & Ifitm6 & interferon induced transmembrane protein 6 & -3.128 \\
\hline Lrrc15 & leucine rich repeat containing 15 & 2.110 & Myb & myeloblastosis oncogene & -3.111 \\
\hline
\end{tabular}

\section{Pathway analysis}

Different bioinformatics tools were used for analysis of the large dataset with emphasis on the identification of pathways differentially regulated between the $F r z b^{-/-}$and wild-type mice. The PANTHER pathway analysis is shown in Table 2. Among the up-regulated pathways the ECM-associated integrin pathway, the cadherin pathway, as well as WNT signaling, were most striking from a biological perspective. Down-regulated pathways pointed towards inflammation and immune cascades, the cell cycle, p53 activation and again integrins (Table 2 ). Associations of the differentially regulated gene set using databases defining "biological processes" as analysed by PANTHER are shown in the additional materials (see Additional file 3).

We also applied the DAVID bioinformatics tools specifically interrogating gene representation in KEGG and Biocarta databases. Again, pathways associated with WNT signaling, cell adhesion and ECM interactions were most prominent among the up-regulated gene sets and appeared relevant from a biological perspective (see Additional file 4). Members of transforming growth factor-beta (TGF $\beta$ ) superfamily signaling, including bone morphogenetic proteins (BMPs), were also up-regulated. Pathways among the down-regulated gene list were again linked to p53 signaling and the cell cycle, and to different systems associated with immunity and inflammation. The GSEA analysis further confirmed positive associations between $\mathrm{Frzb}^{-1-}$ mice and ECM interactions as well as negative associations with the cell cycle (see Additional file 5). No miRNAs were associated with the $\mathrm{Frzb}^{-/}$or wild-type phenotype using the stringent limit (nominal $P$-value $<0.001$ and FDR q-value $<0.01$ ). Only miRNA-147 had a nominal $P$-value $<0.001$ and a FDR q-value $<0.25(0.17)$. This miRNA has been associated with WNT and ECM pathways [40] (Table 3). In the transcription factor analysis, motifs associated with Foxd1, Znf238 and Pbx1 had nominal P-values $<0.001$ and FDR q-values $<0.05$. Foxd1 has been suggested as a WNT target gene in the developing chick retina [41] (Table 3). In addition, two motifs without specific transcription factor association were also enriched with $P$ values < 0.001 and FDR q-values < 0.05 (Table 3). Genes overexpressed in the wild-type mice compared to 
Table 2 PANTHER analysis of differentially expressed genes by pathway.

\begin{tabular}{|c|c|c|c|c|}
\hline Pathway & $\begin{array}{l}\text { number of genes in } \\
\text { reference list }\end{array}$ & $\begin{array}{l}\text { number of regulated } \\
\text { genes }\end{array}$ & $\begin{array}{l}\text { Expected number of } \\
\text { genes }\end{array}$ & $P$-value* \\
\hline \multicolumn{5}{|c|}{ Pathways that are overrepresented taking up-regulated genes into account } \\
\hline Integrin signaling pathway & 185 & 19 & 3.48 & 4.78E-09 \\
\hline WNT signaling pathway & 348 & 22 & 6.55 & 1.27E-06 \\
\hline Angiogenesis & 193 & 12 & 3.63 & $3.76 \mathrm{E}-04$ \\
\hline Cadherin signaling pathway & 167 & 11 & 3.14 & 4.07E-04 \\
\hline Alzheimer disease-presenilin pathway & 124 & 9 & 2.33 & $6.84 \mathrm{E}-04$ \\
\hline \multicolumn{5}{|c|}{ Pathways that are overrepresented taking downregulated genes into account } \\
\hline B cell activation & 87 & 21 & 3.01 & $1.03 \mathrm{E}-11$ \\
\hline p53 pathway & 127 & 18 & 4.39 & $8.32 \mathrm{E}-07$ \\
\hline $\begin{array}{c}\text { Inflammation mediated by chemokine and cytokine } \\
\text { signaling pathway }\end{array}$ & 298 & 29 & 10.30 & 1.12E-06 \\
\hline Blood coagulation & 55 & 10 & 1.90 & 2.96E-05 \\
\hline p53 pathway feedback loops 2 & 51 & 9 & 1.76 & 9.15E-05 \\
\hline Parkinson disease & 106 & 13 & 3.66 & 1.13E-04 \\
\hline Cell cycle & 24 & 6 & 0.83 & $2.21 \mathrm{E}-04$ \\
\hline Integrin signaling pathway & 185 & 17 & 6.39 & $3.38 \mathrm{E}-04$ \\
\hline De novo pyrimidine deoxyribonucleotide biosynthesis & 23 & 5 & 0.79 & 1.36E-03 \\
\hline DNA replication & 25 & 5 & 0.86 & $1.95 \mathrm{E}-03$ \\
\hline Ras Pathway & 80 & 9 & 2.76 & 2.20E-03 \\
\hline Apoptosis signaling pathway & 141 & 12 & 4.87 & 4.37E-03 \\
\hline$T$ cell activation & 142 & 12 & 4.91 & 4.61E-03 \\
\hline JAK/STAT signaling pathway & 20 & 4 & 0.69 & $5.48 \mathrm{E}-03$ \\
\hline Angiogenesis & 193 & 14 & 6.67 & $8.51 \mathrm{E}-03$ \\
\hline \multicolumn{5}{|c|}{ Pathways that are overrepresented taking up- and down-regulated genes into account } \\
\hline Integrin signaling pathway & 185 & 36 & 9.87 & 7.87E-09 \\
\hline B cell activation & 87 & 24 & 4.64 & 7.10E-09 \\
\hline $\begin{array}{c}\text { Inflammation mediated by chemokine and cytokine } \\
\text { signaling pathway }\end{array}$ & 298 & 41 & 15.90 & 2.42E-06 \\
\hline p53 pathway & 127 & 21 & 6.78 & 1.79E-04 \\
\hline Angiogenesis & 193 & 26 & 10.30 & 4.45E-04 \\
\hline Blood coagulation & 55 & 12 & 2.93 & 8.00E-04 \\
\hline p53 pathway feedback loops 2 & 51 & 9 & 2.72 & $2.42 \mathrm{E}-02$ \\
\hline Cell cycle & 24 & 6 & 1.28 & 2.19E-02 \\
\hline WNT signaling pathway & 348 & 31 & 18.57 & 4.57E-02 \\
\hline Axon guidance mediated by netrin & 29 & 6 & 1.55 & 4.36E-02 \\
\hline Parkinson disease & 106 & 13 & 5.66 & 4.22E-02 \\
\hline
\end{tabular}

* P-values are obtained by the binomial test; only $P$-values that fulfilled an additional false discovery rate test are shown.

the $\mathrm{Frzb}^{-/-}$mice were associated with different members of the E2F family of transcription factors applying the stringent criteria. E2F1 has been negatively associated with WNT signaling [42].

\section{Detailed pathway analysis}

We focused on a detailed analysis of changes in the WNT, the integrin/cadherin/ECM and the cell cycle pathways. Many genes mapped in the down-regulated inflammation-associated signaling systems were specifically linked to immune cell populations present in the bone marrow and were not further taken into account for this study.
The WNT pathway gene set demonstrated up-regulation of different extracellullar WNT antagonists in the $\mathrm{Frzb}^{-1-}$ mice as compared to wild-types. These genes belonged to the SFRP/FRZB-family, to the DKK family and to a group of intracellular WNT pathway modulators (Table 4 - compiled from PANTHER and DAVID analysis). Different frizzled (FZD) receptors were upregulated and there was evidence for activation of both canonical and non-canonical signaling with increased expression of target genes, such as Rspo2, Wisp2, Sox17, Tbl1x and Acta2, and of intracellular messenger molecules $N f a t c 2$ and 4 that are activated in the calciumdependent WNT pathway (Table 4). 
Table 3 miRNAs and transcription factors motifs for genes up-regulated in the Frzb $^{-/-}$mice

\begin{tabular}{|c|c|c|c|c|}
\hline Name/Responsive Element sequence & Description & Enrichment Score & Nominal $P$-value & FDR* q-value \\
\hline \multicolumn{5}{|l|}{ miRNA associations in $\mathrm{Frzb}^{-/-}$samples } \\
\hline miR-147 & microRNA-147 & 0.49 & 0.000 & 0.172 \\
\hline \multicolumn{5}{|c|}{ Transcription factor associations in $\mathrm{Frzb}^{-/-}$samples } \\
\hline FoxD1 & forkhead box D1 & 0.48 & 0.000 & 0.027 \\
\hline Znf238 & zinc finger protein 238 & 0.45 & 0.000 & 0.018 \\
\hline $\mathrm{Pbx} 1$ & pre B-cell leukemia transcription factor 1 & 0.49 & 0.000 & 0.014 \\
\hline RYTAAWNNNTGAY & No matching TCF & 0.58 & 0.000 & 0.037 \\
\hline AAANWWTGC & No matching TCF & 0.43 & 0.000 & 0.018 \\
\hline
\end{tabular}

*False discovery rate (FDR)

Confirmation experiments by RT-PCR showed lack of Frzb, significant up-regulation of Sfrp1, Sfrp2 and a similar trend for Dkk2 (Figure 2A). This up-regulation of other antagonists may represent a compensatory mechanism to minimise the effects of WNT pathway activation in $\mathrm{Frzb}^{-/-}$mice. Western blot analysis showed only discrete amounts of these different antagonists in the dissected material and did not allow for reliable quantification of the individual proteins (data not shown). Baseline activation of the canonical signaling pathway was indeed not found different between $F r z b^{-/-}$ and wild-type mice as demonstrated by Western blot and quantitative analysis by densitometry for the active form of $\beta$-catenin (Figure 2B). Also, Western blot for intracellular messengers of the BMP pathway, P-Smad $1 / 5 / 8$, showed no striking differences between wild-type and $\mathrm{Frzb}^{-/-}$mice suggesting maintenance of WNT and BMP pathway balance at the tissue level in unchallenged mice (Figure 2C). However, further comparison of the list with genes up-regulated in the $F r z b^{-1-}$ mice with a user-compiled list of WNT target genes (see Additional file 1), did reveal consistent up-regulation of such targets indicating that more subtle changes at the molecular level are present (Yates corrected Chi-square test $P<$ 0.0001).

Although we did not previously find structural abnormalities or spontaneous development of OA in $\mathrm{Frzb}^{-1-}$ mice, expression of ECM components and cell adhesion molecules showed a shift in this genetic model (Table 5). In particular, a number of collagens were differentially regulated and specific changes in integrins were found. Some of these link to the articular cartilage while others are more likely associated with the subchondral bone and with small vessels.

We performed complementary gain of function experiments to test the effect of FRZB on chondrogenesis and ECM composition in micro-masses from the mouse chondrogenic ATDC5 cell line. Expression of both Col2a1 and aggrecan was significantly increased in ATDC5 micro-masses overexpressing FRZB as compared to controls (Figure 3A). Staining for collagen content (Picrosirius Red) and sulphated glycosaminoglycans (GAGs) (Safranin O) at Day 7 revealed some changes in the morphology of micro-masses overexpressing FRZB. Collagen fibers and sulphated GAG distribution in these micro-masses seemed to have spread out more from the center compared to the controls (Figure $3 B$ ). Protein quantification of the micro-masses was, however, comparable between the two groups suggesting that the appearance reflects increased migration of ATDC5 cells overexpressing FRZB (Figure 3C). Quantification of the stainings was not different between micro-masses overexpressing FRZB and controls for Picrosirius Red. For Safranin O staining intensity was mildly but significantly decreased in micro-masses overexpressing FRZB (Figure 3D). Conversely silencing of $F r z b$ resulted in down-regulation of these genes (Figure 3E). RT-PCR analysis of other collagens, in particular Col3a1 and Col5a1, significantly up-regulated in the $\mathrm{Frzb}^{-/-}$mice compared to wild-type mice in the microarray analysis, depicted a decreasing trend at Day 7 in $F R Z B$ overexpressing micro-masses compared to the control micro-masses; however, these comparisons did not reach statistical significance (Figure 4A). A similar down-regulation compared to controls was seen during differentiation after silencing of Frzb (Figure 4B), which can be explained by the lack of chondrogenesis. In silico promoter analysis of these collagens, including Col5a3, which was also significantly up-regulated in $\mathrm{Frzb}^{-/-}$samples, indicated the presence of several TCF/LEF responsive elements known from literature [39] in each of the gene promoters matching at least $80 \%$ of the original sequence. Moreover, each promoter contained a unique $100 \%$ consensus sequence in the promoter region indicating a direct link by which FRZB could modulate transcription of these genes (Table 6). Further analysis also showed the presence of binding sites for other transcription factors linked to WNT signaling such as Oct-1, EP300, Gata and AP-1.

Among the down-regulated pathways and processes, effects on the cell cycle and partially overlapping p53 signaling were most striking (Table 7). Down-regulation 
Table 4 Genes linked to WNT signaling that are significantly up- or down-regulated

\begin{tabular}{|c|c|c|}
\hline Symbol & Name & Function \\
\hline \multicolumn{3}{|c|}{ Up-regulated genes in $\mathrm{Frzb}^{-/-}$mice } \\
\hline \multicolumn{3}{|c|}{ WNT target genes } \\
\hline Acta2 & actin, alpha 2, smooth muscle, aorta & Target gene \\
\hline Rspo2 & R-spondin 2 homolog (Xenopus laevis) & Target gene and stimulates WNT/ $\beta$-catenin pathway \\
\hline Sox17 & SRY-box containing gene 17 & Target gene \\
\hline$T b / 1 x$ & transducin (beta)-like 1X-linked & $\begin{array}{l}\text { Target gene and adaptor with the ubiquitin-conjugating/19S } \\
\text { proteasome }\end{array}$ \\
\hline Wisp2 & WNT1 inducible signaling pathway protein 2 & Target gene \\
\hline \multicolumn{3}{|c|}{ WNT antagonists } \\
\hline Dkk2 & dickkopf homolog 2 (Xenopus laevis) & Extracellular WNT antagonist \\
\hline Dkk3 & dickkopf homolog 3 (Xenopus laevis) & Extracellular WNT antagonist \\
\hline Nkd1 & naked cuticle 1 homolog (Drosophila) & Intracellular antagonist \\
\hline Nkd2 & naked cuticle 2 homolog (Drosophila) & Intracellular antagonist \\
\hline Sfrp 1 & secreted frizzled-related protein 1 & Extracellular WNT antagonist \\
\hline Sfrp2 & secreted frizzled-related protein 2 & Extracellular WNT antagonist \\
\hline Sfrp4 & secreted frizzled-related protein 4 & Extracellular WNT antagonist \\
\hline \multicolumn{3}{|c|}{ WNT receptor } \\
\hline Fzdl & frizzled homolog 1 (Drosophila) & WNT receptor \\
\hline$F z d 2$ & frizzled homolog 2 (Drosophila) & WNT receptor \\
\hline$F z d 8$ & frizzled homolog 8 (Drosophila) & WNT receptor \\
\hline \multicolumn{3}{|c|}{ Intracellular messenger molecules } \\
\hline Nfatc2 & $\begin{array}{l}\text { nuclear factor of activated T-cells, cytoplasmic, calcineurin- } \\
\text { dependent } 2\end{array}$ & Intracellular messenger in non-canonical calcium-dependent pathway \\
\hline Nfatc4 & $\begin{array}{l}\text { nuclear factor of activated T-cells, cytoplasmic, calcineurin- } \\
\text { dependent } 4\end{array}$ & Intracellular messenger in non-canonical calcium-dependent pathway \\
\hline Prickl2 & prickle homolog 2 (Drosophila) & Intracellular messenger in non-canonical planar cell polarity pathway \\
\hline \multicolumn{3}{|c|}{ Receptors of the TGF $\beta$ superfamily pathway } \\
\hline Acvrl & activin A receptor, type I & type I receptor for the TGF $\beta$ family \\
\hline Acvrlc & activin A receptor, type IC & type I receptor for the TGF $\beta$ family \\
\hline Bmprlb & bone morphogenetic protein receptor, type 1B & type I receptor for the TGF $\beta$ family \\
\hline \multicolumn{3}{|c|}{ Cell adhesion molecules } \\
\hline Cdh13 & cadherin 13 & Cell adhesion molecule \\
\hline Dchs1 & dachsous homolog 1 (Drosophila) - protocadherin 16 & Cell adhesion molecule \\
\hline Pcdh9 & protocadherin 9 & Cell adhesion molecule \\
\hline Pcdh17 & protocadherin 17 & Cell adhesion molecule \\
\hline Pcdh18 & protocadherin 18 & Cell adhesion molecule \\
\hline Pcdh19 & protocadherin 19 & Cell adhesion molecule \\
\hline \multicolumn{3}{|c|}{ Down-regulated genes in $\mathrm{Frzb}^{-/-}$mice } \\
\hline \multicolumn{3}{|c|}{ WNT antagonists } \\
\hline$D k k 1$ & dickkopf homolog 1 (Xenopus laevis) & Extracellular WNT antagonist \\
\hline Btrc & beta-transducin repeat containing & Stimulates $\beta$-catenin ubiquitinilation \\
\hline \multicolumn{3}{|c|}{ WNT receptor scaffolds } \\
\hline Arrb1 & beta-arrestin 1 & scaffold in intracellular WNT receptor complex \\
\hline Arrb2 & Beta-arrestin 2 & \\
\hline
\end{tabular}

of different cyclins and cyclin kinases as well as many other positive regulators of the cell cycle suggest inhibition of mitosis and cell proliferation. Ribcage chondrocytes derived from $\mathrm{Frzb}^{-/-}$mice proliferated significantly less than those derived from the wild-type mice in vitro after one week, corroborating the effect of FRZB on chondrocyte proliferation (Figure 4C).

\section{Discussion}

Our transcriptome analysis of the bone-cartilage biomechanical unit of $\mathrm{Frzb}^{-/-}$and wild-type mice provides evidence for tight regulation of WNT signaling, shifts in ECM component synthesis and alterations in cell proliferation and differentiation. FRZB is a secreted WNT antagonist, originally identified from a chondrogenic 


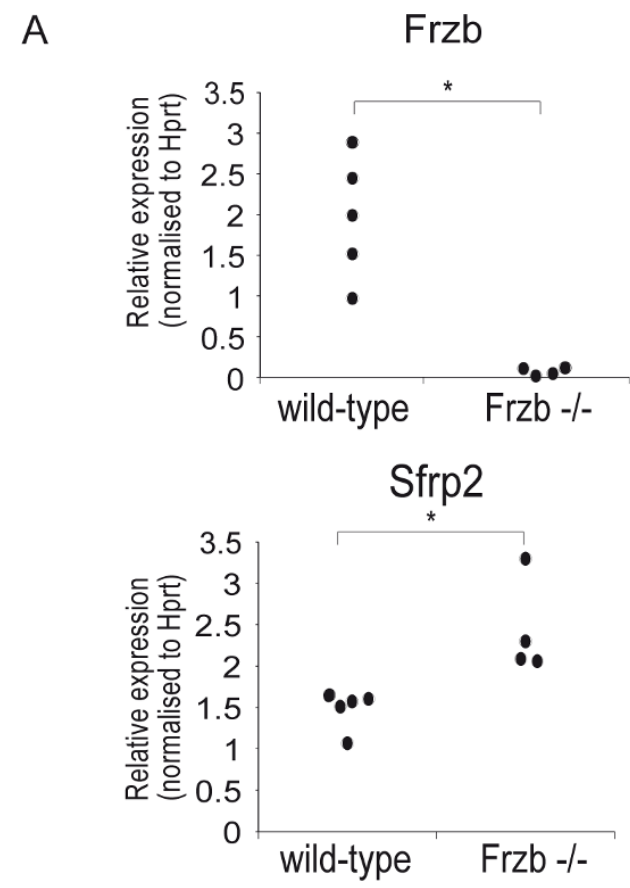

B

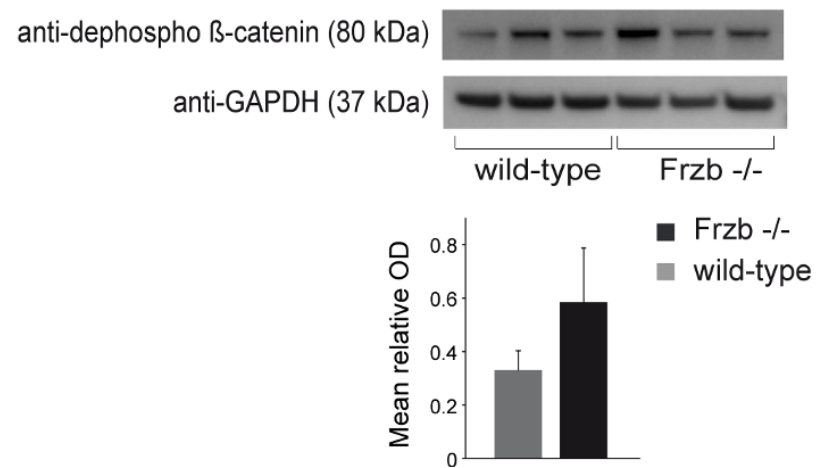

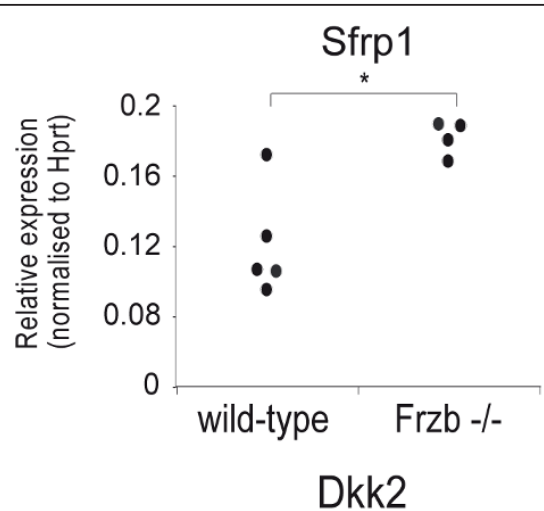

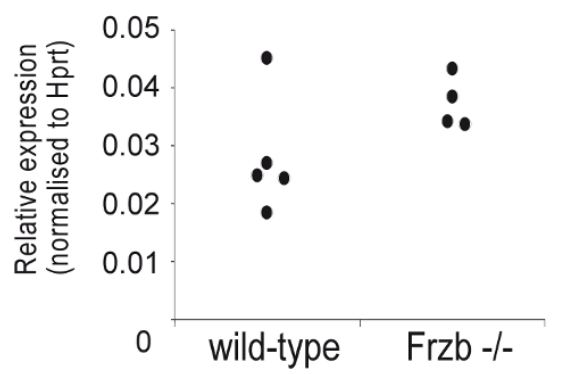

C

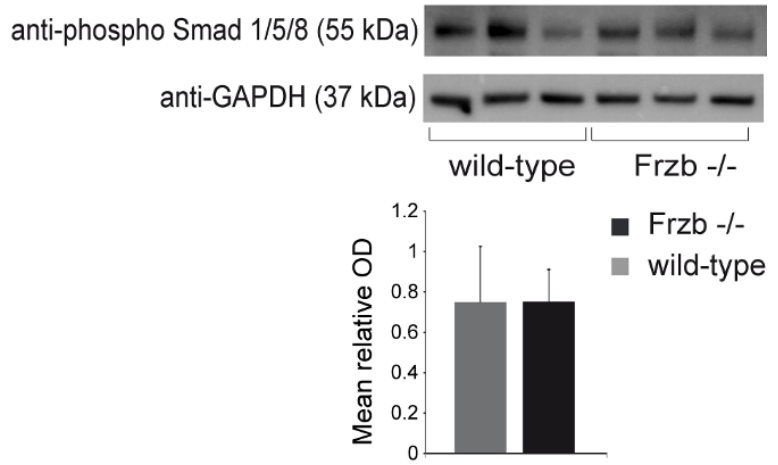

Figure 2 Molecular analysis of the articular cartilage - subchondral bone to corroborate the microarray data. (A) Real-Time PCR analysis of tibia articular cartilage and subchondral bone from frizzled-related protein-knockout (Frz $b^{-1}$ ) mice compared to wild-types. Frzb was virtually absent and secreted frizzled-related protein 1 (Sfrp1) and secreted frizzled-related protein 2 (Sfrp2) were significantly upregulated in Frzb ${ }^{-1}$ samples compared to wild-type samples. There was a trend of up-regulation for dickkopf homolog 2 (Dkk2) (one outlier). Data are shown as relative expression values versus hypoxanthine guanine phosphoribosyl transferase (Hprt) $\left(2^{-\Delta C t}\right)\left(n=\right.$ four Frzb $b^{-/}$and five wild-type samples; All experiments were performed in duplicate; Mann-Whitney test: $P=0.016$ for Frzb, $P=0.032$ for Sfrp1, $P=0.016$ for Sfrp2 and $P=0.2$ for Dkk2). (BC) Western blot and densitometry analysis of proteins extracted from tibia articular cartilage and subchondral bone showed no consistent change in active (dephospho) $\beta$-catenin (80 kDa) (B) and phosphorylated (phospho) Smad 1/5/8 (mothers against decapentaplegic homolog) (55 $\mathrm{kDa}$ ) (C) between three wild-type (lane 1-3) and in three $\mathrm{Frzb}^{-1-}$ (lane 4-6) samples. Anti-GAPDH (glyceraldehyde-3-phosphate dehydrogenase) (37 $\mathrm{kDa}$ ) Western blot is shown as loading control. Quantitative analysis was performed with Image J software. Data are shown as the ratio of the mean optical density (OD) for $\beta$-catenin or P-Smad/the mean OD of GAPDH ( $n=$ three samples/group; Mann-Whitney test: $P>0.05$ for $\beta$ catenin and for P-Smad).

extract of bovine articular cartilage [17] and misexpression of $F R Z B$ in the chick limb inhibits chondrocyte hypertrophy [18]. Polymorphisms in the human FRZB gene have been associated with OA [3], although this link has been debated recently [43].
Here, absence of Frzb in the articular cartilage and subchondral bone induces a subtle increase in WNT signaling evident by up-regulation of several WNT target genes as demonstrated by pathway analysis and by comparison with a user-compiled list of WNT target genes. 
Table 5 Genes related to ECM matrix and cell adhesion

\begin{tabular}{|c|c|c|}
\hline Symbol & Name & Function \\
\hline \multicolumn{3}{|c|}{ Up-regulated genes in $\mathrm{Frzb}^{-1-}$ mice } \\
\hline \multicolumn{3}{|c|}{ Collagens } \\
\hline Col3al & Collagen alpha-1(III) chain & Fibril forming collagen - co-distributes with type I collagen \\
\hline Col4ar & Collagen alpha-1(IV) chain & Basal lamina collagen \\
\hline Col4a2 & Collagen alpha-2(IV) chain & Basal lamina collagen \\
\hline Col4a4 & Collagen alpha-4(IV) chain & Basal lamina collagen \\
\hline Col4a5 & Collagen alpha-5(IV) chain & Basal lamina collagen \\
\hline Col4a6 & Collagen alpha-6(IV) chain & Basal lamina collagen \\
\hline Col5al & Collagen alpha-1(V) chain & Fibril forming collagen - co-distributes with type I collagen \\
\hline Col5a3 & Collagen alpha-3(V) chain & $\begin{array}{l}\text { Fibril forming collagen - co-distributes with type I collagen Type V } \\
\text { collagen }\end{array}$ \\
\hline Col8a2 & Collagen alpha-2(VIII) chain & Basal lamina collagen \\
\hline Col12ar & Collagen alpha-1(XII) chain & FACIT collagen \\
\hline Col14a1 & Collagen alpha-1(XIV) chain & FACIT collagen \\
\hline Col15ar & Collagen alpha-1(XVIII) chain & Antiangiogenic factor - pericellular matrix \\
\hline Col16a1 & Collagen alpha-1(XVI) chain & FACIT-collagen \\
\hline Col18a1 & Collagen alpha-1(XVIII) chain & antiangiogenic factor - pericellular matrix \\
\hline \multicolumn{3}{|c|}{ Integrins } \\
\hline $\operatorname{ltg} a 8$ & Integrin alpha-8 light chain & RGD-binding integrin \\
\hline $\mid \operatorname{tg} b / 1$ & Integrin beta-like protein 1 & Type B like integrin \\
\hline$S d c 2$ & syndecan 2 & Heparan proteoglycan transmembrane protein \\
\hline \multicolumn{3}{|c|}{ Growth factors and receptors } \\
\hline Egfr & epidermal growth factor receptor & Receptor for epidermal growth factor \\
\hline $\lg f 1$ & insulin-like growth factor 1 & Growth factor stimulating ECM synthesis \\
\hline Pdgfra & platelet derived growth factor receptor alpha chain & Receptor for platelet derived growth factors \\
\hline Vegfc & vascular endothelial growth factor $\mathrm{c}$ & Pro-angiogenic factor - Flt4 ligand \\
\hline Lims2 & LIM and senescent cell antigen-like-containing domain protein 2 & Focal adhesion molecule \\
\hline \multicolumn{3}{|c|}{ Cytoskeleton molecules } \\
\hline Acta2 & Actin, aortic smooth muscle & \\
\hline Parva & Alpha-parvin & Actin binding protein \\
\hline $\mathrm{VCl}$ & Vinculin & Actin binding protein \\
\hline \multicolumn{3}{|c|}{ Extracellular matrix - integrin interacting molecules } \\
\hline Lamb1 & laminin B1 subunit 1 & Extracellular matrix glycoprotein \\
\hline Lamg1 & laminin, gamma 1 & Extracellular matrix glycoprotein \\
\hline Npnt & nephronectin & Ligand for integrin alpha 8/b1 \\
\hline$T n n$ & tenascin $N$ & Extracellular matrix glycoprotein \\
\hline $\operatorname{Tn} \times b$ & tenascin XB & Extracellular matrix glycoprotein \\
\hline Thbs2 & thrombospondin 2 & Extracellular matrix glycoprotein \\
\hline Thbs4 & thrombospondin 4 & Extracellular matrix glycoprotein \\
\hline \multicolumn{3}{|c|}{ Down-regulated genes in $\mathrm{Frzb}^{-/-}$mice } \\
\hline \multicolumn{3}{|c|}{ Integrins } \\
\hline $\operatorname{ltga4}$ & Integrin alpha-4 & \\
\hline Itgal & Integrin alpha-L & \\
\hline Itgam & Integrin alpha-M & \\
\hline ltgb2 & Integrin beta-2 & \\
\hline$|\operatorname{tg} b 2|$ & Integrin beta-2-like protein & \\
\hline \multicolumn{3}{|c|}{ Focal adhesion molecule } \\
\hline Lims1 & LIM and senescent cell antigen-like-containing domain protein 1 & Focal adhesion molecule \\
\hline \multicolumn{3}{|c|}{ Cytoskeleton molecules } \\
\hline Parvb & Beta-parvin & Actin binding protein \\
\hline \multicolumn{3}{|l|}{ Kinases } \\
\hline$\overline{\text { Map3k1 }}$ & Mitogen-activated protein kinase kinase kinase 1 & Mitogen activated kinase \\
\hline
\end{tabular}


Table 5 Genes related to ECM matrix and cell adhesion (Continued)

\begin{tabular}{cll}
\hline Mapk13 & Mitogen-activated protein kinase 13 & Mitogen activated kinase \\
Grap2 & GRB2-related adaptor protein 2 & Adapator protein \\
Lck & Proto-oncogene tyrosine-protein kinase LCK & T cell specific kinase \\
Pik3cd & $\begin{array}{l}\text { Phosphatidylinositol-4,5-bisphosphate 3-kinase catalytic subunit delta } \\
\text { isoform }\end{array}$ & Phosphoinositide 3-kinases \\
Pik3cg & $\begin{array}{l}\text { Phosphatidylinositol-4,5-bisphosphate 3-kinase catalytic subunit } \\
\text { gamma isoform }\end{array}$ & Phosphoinositide 3-kinases \\
\hline
\end{tabular}

Absence of $F r z b$ also results in the up-regulation of other SFRP family members and different WNT modulators, suggesting that compensatory mechanisms exist in order to tightly control WNT signaling in these tissues. We previously demonstrated that $\mathrm{Frzb}^{-1-}$ mice show increased articular cartilage damage in different induced models of OA, although we did not see signs of spontaneous accelerated OA development in one-year old mice [7]. This contrasts with more direct and radical changes in the WNT canonical cascade as both tissuespecific gain and loss of function of $\beta$-catenin, result in premature OA $[8,9]$.

FRZB can modulate both canonical and non-canonical WNT signaling. New insights into the differential activation of these pathways in articular chondrocytes may help to further explain why deletion of a single antagonist induces only subtle changes as compared to the dramatic effects of $\beta$-catenin modulation. Distinct SFRPs do not bind different WNTs with similar affinities and their effect may depend on the cell type and interactions with other pathways [44]. Nalesso et al. demonstrated that low amounts of WNT ligand can activate noncanonical signaling whereas higher amounts activate the $\beta$-catenin mediated pathway [45]. Moreover, inhibition of either pathway can de-repress the alternative one. In their system, Wnt3a induced articular chondrocyte dedifferentiation by activating the non-canonical $\mathrm{Ca}^{2+} / \mathrm{CaM}-$ KII pathway and stimulated proliferation by activating the canonical pathway.

The changes we detected are not limited to the articular cartilage. Increased WNT signaling in the subchondral bone can also contribute to OA development. In this context, local regulatory mechanisms may be different from tissue to tissue. $F r z b^{-1-}$ mice appear to have normal subchondral bone but increased cortical bone thickness [7]. Also, anabolic responses in the cortical bone to cyclic loading are much greater in $\mathrm{Frzb}^{-1-}$ mice compared to wild-types [7].

Absence of FRZB resulted in shifts in collagens, integrins and cadherins. Among these, changes in type III and type $\mathrm{V}$ collagen are of interest. As articular cartilage matures and ages, collagen fibrils become thicker, the amount of types IX and XI collagens decreases relative to type II collagen [46], and these minor collagens are progressively replaced by type V collagen [47]. Type III collagen can be detected in small but significant amounts in articular cartilage of mature joints and is cross-linked to the surface of type II collagen [46]. Its presence is more prominent in OA $[48,49]$. The type III collagen content in articular cartilage tends to vary between individual joints, anatomical location and tissue microanatomy. It may also be dependent on the history of injuries and the wear and tear experienced by a normal joint [46]. Therefore, it seems likely that type III collagen is synthesised as a modifier of existing fibril networks in response to tissue and matrix damage [46]. Although no increased cartilage damage was found in unchallenged $\mathrm{Frzb}^{-/-}$mice, the significant up-regulation of Col5a1, Colsa3 and Col3a1 in the articular cartilage and subchondral bone from $F r z b^{-/-}$mice, suggests increased damage and repair in the $F r z b^{-1-}$ mice at the molecular level.

These observations were further corroborated by complementary experiments where $F R Z B$ was overexpressed in the ATDC5 in vitro chondrogenesis model. Under these conditions, expression of both Col3a1 and Col5a1 was decreased during chondrogenic differentiation, suggesting that either FRZB by itself, or by modulating WNT signaling, affects expression of these ECM molecules in different systems. The additional observation that silencing of $F r z b$ also results in a decrease in these collagens can be explained by lack of chondrogenic differentiation in the latter system.

We also found that overexpression of $F R Z B$ appeared to stimulate chondrogenesis in this model, as shown by increased aggrecan and col2a1 expression. Matured aggrecan monomers in the cartilage are glycosylated macro-molecules in which the glycoconjugates are formed by sulphatation of GAG side chains on the core protein [50]. The amount of sulphated GAGs in the micro-masses, measured by Safranin O staining, was surprisingly decreased in FRZB overexpressing micromasses. Although the differences we observed were limited, these results might suggest that FRZB overexpression in this system impairs the maturation of these aggrecan monomers, for instance, by a relative excess in substrate due to the higher expression levels. Staining for collagens by Picrosirius Red indicated no major 


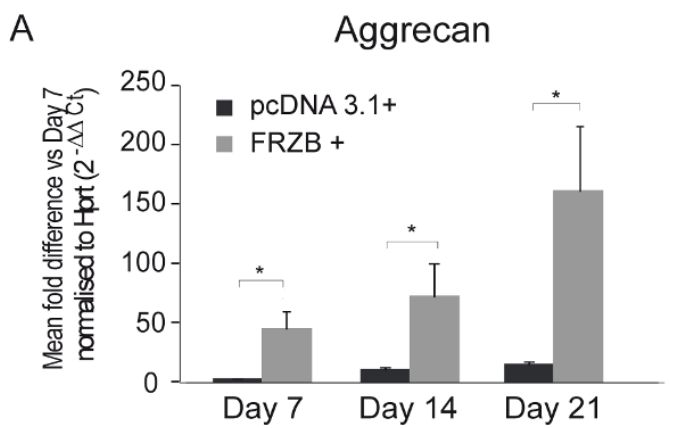

B

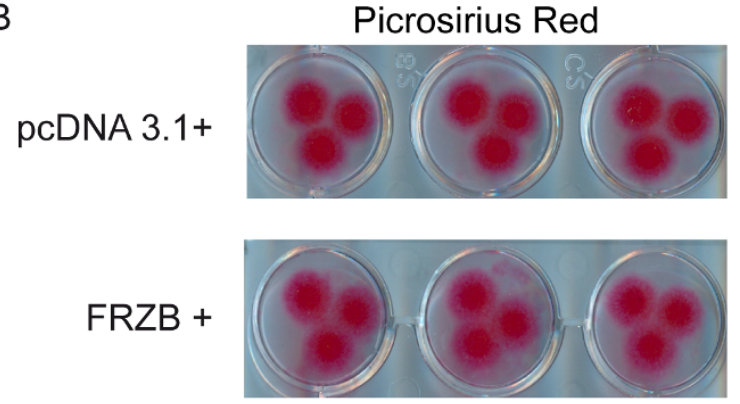

C

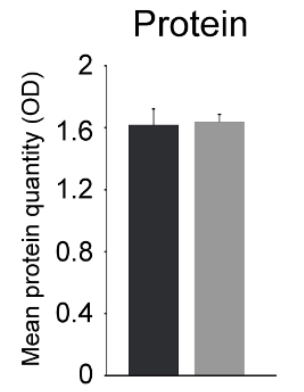

D

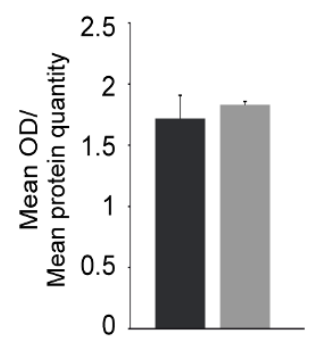

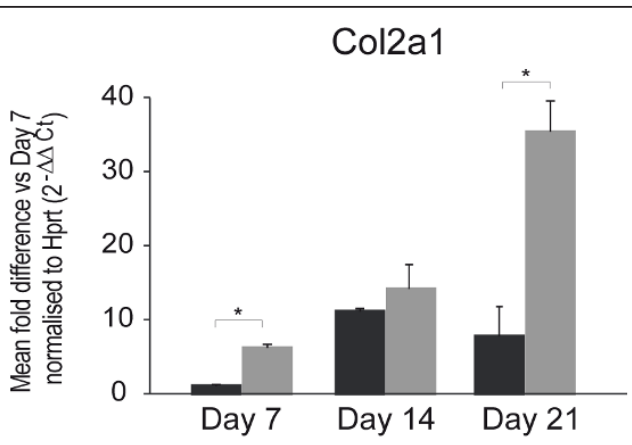

Safranin $\mathrm{O}$
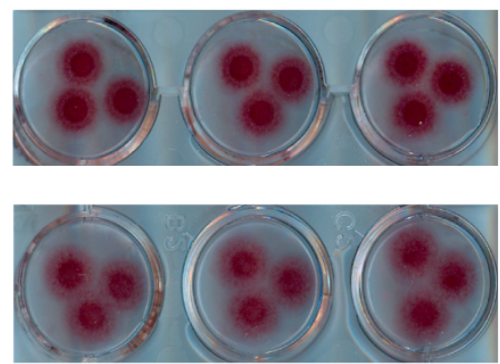

Safranin O

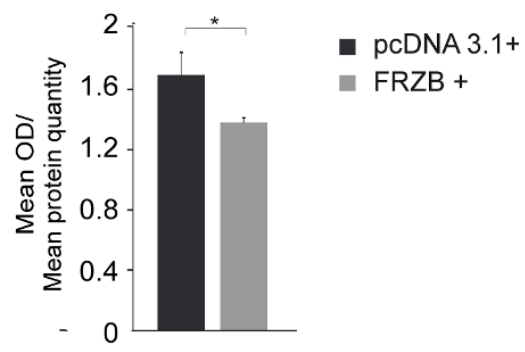

E

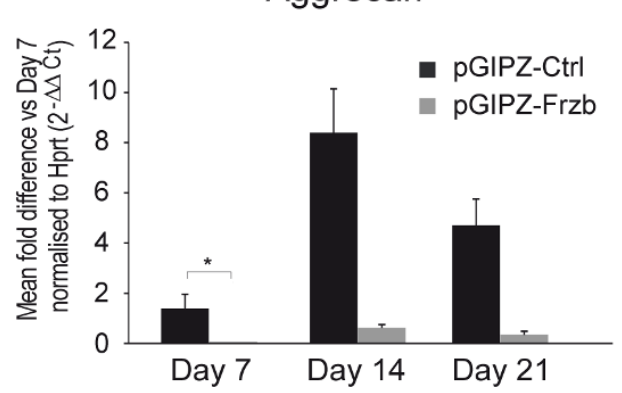

Col2a1

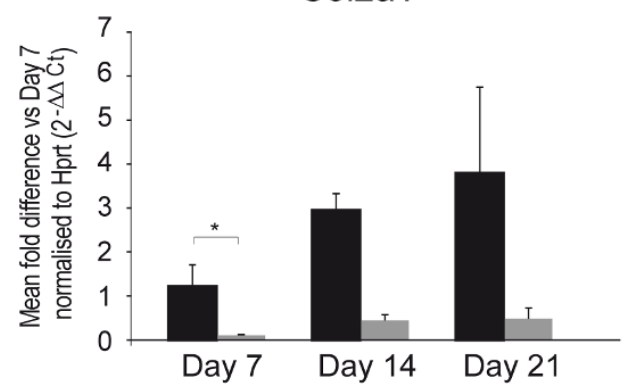

Figure 3 Chondrogenesis after gain or loss of FRZB in ATDC5 cells. (A) Real-Time PCR analysis showed increased expression of collagen type 2a1 (Col2a1) and aggrecan in the micro-masses overexpressing frizzled-related protein (FRZB) compared to micro-masses expressing control pcDNA3.1+ vector. Data are shown as the mean of the fold difference compared to the control condition at Day 7 normalised to hypoxanthine guanine phosphoribosyl transferase $(H p r t)\left(2^{-\Delta \Delta C t}\right) \pm \operatorname{SEM}(n=$ six samples/condition; Mann-Whitney test: for aggrecan $P=0.002, P=0.015$ and $P$ $=0.002$ and for Col2a1 $P=0.03, P=0.3$ and $P=0.002$ ). (B) Picrosirius Red and Safranin $\mathrm{O}$ staining at Day 7 showed increased spreading of collagen fibers and sulphated glycosaminoglycans (GAGs) from the center in micro-masses overexpressing FRZB compared to controls. (C) Protein quantification (optical density (OD) measured at $570 \mathrm{~nm}$ ) of the micro-masses was comparable between the two groups $(n=$ three samples/group; Mann-Whitney test: $P>0.05$ ). (D) Staining intensity was comparable between FRZB overexpressing micro-masses and controls for Picrosirius Red and significantly decreased for FRZB overexpressing micro-masses for Safranin O staining. Data are shown as the mean OD normalised to the mean protein content ( $n=$ three samples/group; Mann-Whitney test: $P>0.05$ for Picrosirius Red and $P=0.02$ for Safranin 0 ). (E) Real-Time PCR analysis showed decreased expression of Colzal and aggrecan in the micro-masses where Frzb was knocked down using the pGIPZ-shRNAmir directed against Frzb compared to controls. Data are shown as the mean of the fold difference compared to the control condition at Day 7 normalised to Hprt $\left(2^{-\Delta \Lambda C t}\right) \pm \operatorname{SEM}(n=$ two to three samples for pGIPZ-Ctrl and five to six samples for pGIPZ-FRZB; MannWhitney test: for aggrecan $P=0.02$ and for Col2a1 $P=0.02$ ). At Day 14 and Day 21 for pGIPZ-Ctrl $n=2$ precluding statistical analysis. 


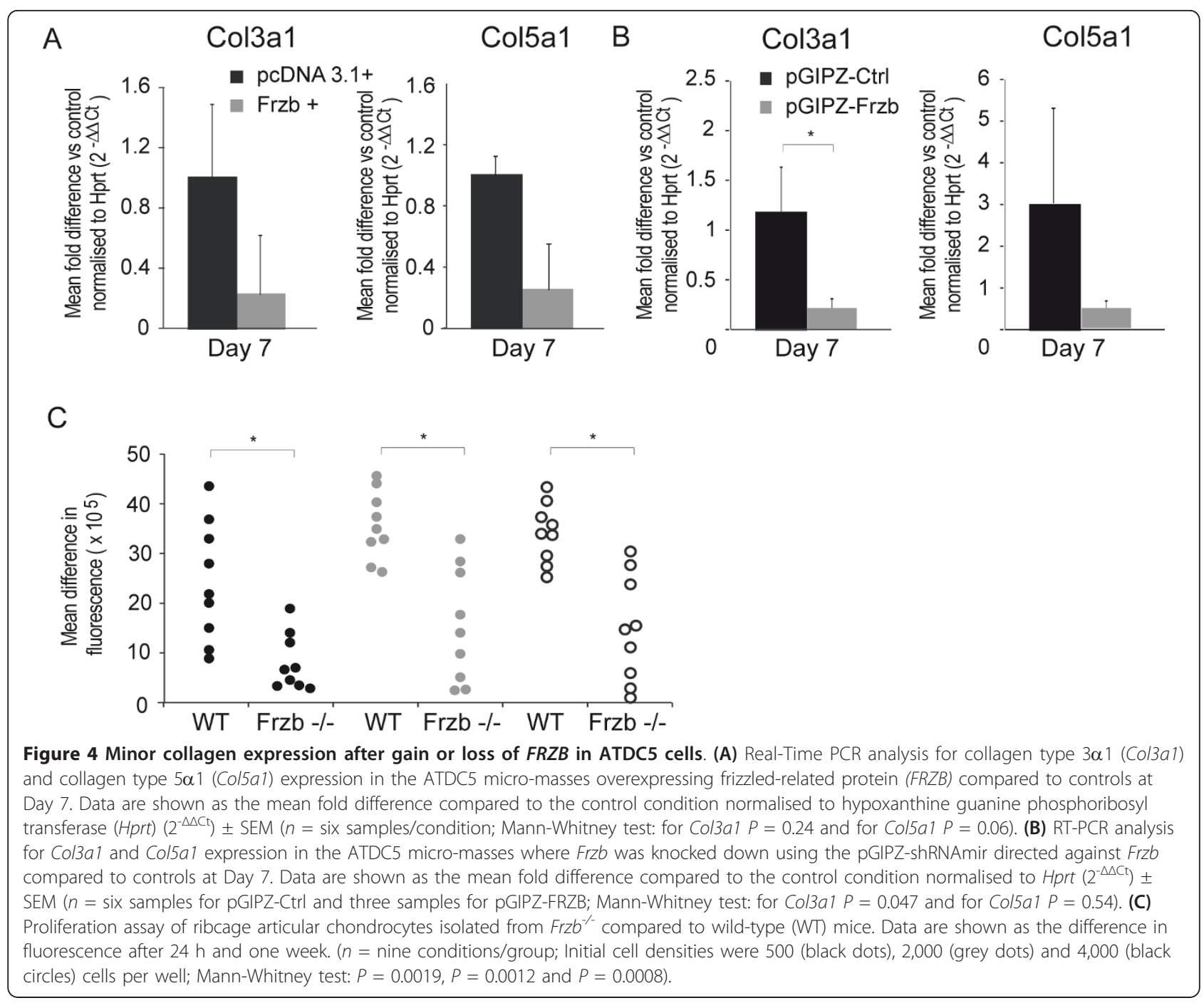

differences in total collagen content in $F R Z B$ overexpressing micro-masses and controls. The observed spreading of the fibers from the center, however, which was also noted in the Safranin O staining, suggests that overexpression of $F R Z B$ could modify matrix distribution, possibly by increasing ATDC 5 migration. All these results are in line with earlier observations on FRZB and chondrogenesis $[17,18]$.

Table 6 TCF/LEF responsive elements (RE) in collagen promoters and matching percentage (\%)

\begin{tabular}{llll}
\hline TCF/LEF RE sequence & Col3a1 & Col5a1 & Col5a3 \\
\hline TTCAAAG & $1 \times 100 \%$ & $1 \times 100 \%$ & $1 \times 85 \%$ \\
CTTGTT & & $3 \times 85 \%$ & $1 \times 85 \%$ \\
CCTTTATC & & $3 \times 78-80 \%$ & $1 \times 80 \%$ \\
CCTTGAT & & $3 \times 85 \%$ & $1 \times 87.5 \%$ \\
CCTTGAA & & $3 \times 85 \%$ & $1 \times 87.5 \%$ \\
ATCAAAG & $1 \times 85 \%$ & $2 \times 85 \%$ & $1 \times 100 \%$ \\
\hline
\end{tabular}

Collagen type III and V are also found in the bone, co-distributed in much lower quantities next to the main collagen component type I collagen. Type V collagen expression is regulated by TGF $\beta$ in osteoblasts during osteogenesis [51]. Since members of the TGF $\beta$ pathway are up-regulated in our $\mathrm{Frzb}^{-1-}$ samples, this may affect expression in the subchondral bone. Collagen type $\mathrm{V}$ is increased in some patients with brittle bone disease and in patients with osteogenesis imperfecta, where collagen type $\mathrm{V}$ likely interferes with the normal process of mineralization [52]. Similar results were found for collagen type III, suggesting a role for collagen type III and V in defects in maturation of the bone [53-57].

The responsive elements for TCF/LEF but also other transcription factors, related to WNT signaling, in the Col3 and Col5 promoters suggest a direct link with WNT signaling by which FRZB can influence the composition of the cartilage and subchondral bone ECM. 
Table 7 Genes linked to the cell cycle that are significantly down-regulated

\begin{tabular}{|c|c|c|}
\hline Symbol & Name & Function \\
\hline \multicolumn{3}{|c|}{ Cyclins and cyclin kinases } \\
\hline Ccna2 & Cyclin a2 & \\
\hline Ccnbl 1 & Cyclin b1 & \\
\hline Ccnb2 & Cyclin b2 & \\
\hline Cond3 & Cyclin d3 & \\
\hline Conel & Cyclin e1 & \\
\hline Ccne2 & Cyclin e2 & \\
\hline$C d k 1$ & Cyclin dependent kinase 1 & \\
\hline$C d k 2$ & Cyclin dependent kinase 2 & \\
\hline \multicolumn{3}{|c|}{ Checkpoint regulators } \\
\hline Bub1 & budding uninhibited by benzimidazoles 1 & Kinase in spindle checkpoint function \\
\hline Bublb & budding uninhibited by benzimidazoles $1 \mathrm{~b}$ & Kinase in spindle checkpoint function \\
\hline Chek1 & CHK1 checkpoint homolog & Checkpoint regulator of cell cycle \\
\hline Chek2 & CHK2 checkpoint homolog & Checkpoint regulator of cell cycle \\
\hline Mad2/1 & mitotic arrest deficient, homolog-like 1 & Mitotic spindle checkpoint \\
\hline \multicolumn{3}{|c|}{ Minichromosome complex } \\
\hline Mcm2 & minichromosome maintenance deficient 2 mitotin & Regulator of cell cycle \\
\hline Mcm4 & minichromosome maintenance deficient 4 & Regulator of cell cycle \\
\hline Mcm5 & minichromosome maintenance deficient 5 & Regulator of cell cycle \\
\hline Mcm6 & minichromosome maintenance deficient 6 & Regulator of cell cycle \\
\hline Mcm7 & minichromosome maintenance deficient 7 & Regulator of cell cycle \\
\hline \multicolumn{3}{|c|}{ Transcription factors } \\
\hline E2F2 & E2F transcription factor 2 & Regulator of cell cycle \\
\hline Tpdp1 & Transcription factor DP1 & Partner of E2F transcription factors \\
\hline Tfdp2 & Transcription factor DP1 & Partner of E2F transcription factors \\
\hline Ttk & Ttk protein kinase & Mitosis associated kinase \\
\hline \multicolumn{3}{|c|}{ Other cell cycle regulators } \\
\hline $\mathrm{Cdc} 6$ & cell division cycle 6 homolog & Regulator of cell cycle \\
\hline Cdc20 & cell division cycle 20 homolog & Regulator of cell cycle \\
\hline Cdc25a & cell division cycle 25 a homolog & Regulator of cell cycle \\
\hline$C d c 25 b$ & cell division cycle 25b homolog & Regulator of cell cycle \\
\hline Cdc45 & cell division cycle 45 homolog & Regulator of cell cycle \\
\hline Dbf4 & DBF4 homolog (S. cerevisiae) & Activator of S-phase kinase \\
\hline Espl1 & extra spindle poles-like 1 & Cleavage of sister chromatids \\
\hline Fzr1 & fizzy/cell division cycle 20 related 1 & Activation of the anaphase promoting complex during mitosis \\
\hline GADD45A & Growth arrest and DNA damage inducible gene $45 \mathrm{a}$ & Regulator of DNA repair and inhibitor of the $S$ phase \\
\hline Orcl & origin recognition complex, subunit 1 & Initiation of DNA replication \\
\hline Orc6 & origin recognition complex, subunit 6 & Initiation of DNA replication \\
\hline$P \mid k 1$ & Polo-like kinase 1 & Promoter of mitosis \\
\hline Pcna & proliferating cell nuclear antigen & Cofactor of DNA polymerase delta \\
\hline$R b 1$ & Retinoblastoma 1 & Regulator of the cell cycle \\
\hline$R b / 1$ & Retinoblastoma like 1 & Regulator of the cell cycle \\
\hline
\end{tabular}

On the other hand, considering the relatively mild effects on WNT signaling at the tissue level, our study also leaves open the possibility that FRZB has unexpected, more robust post-transcriptional or epigenomic effects in these tissues suggesting new directions for research [58].

Loss of Frzb resulted in a decrease of genes associated with cell cycle progression. Proliferation analysis of ribcage chondrocytes isolated from $\mathrm{Frzb}^{-/-}$mice compared to those isolated from wild-type mice agreed with this observation. Canonical WNT signalling is known to promote cell cycle progression and proliferation through the up-regulation of target genes like c-myc and cyclin $\mathrm{D}$, but also via regulation of the mitotic spindle apparatus [59]. This apparent discrepancy where $\mathrm{Frzb}^{-/-}$chondrocytes proliferate slower instead of faster, may be 
dependent on the cell type, the differentiation state, the WNT ligand involved and antagonist interactions. Differences in activation of either canonical or alternative pathways may also play a role.

The analysis presented here has a number of limitations. In particular, the number of samples used in the microarray experiment is small. Extraction of high quality RNA, required for microarray, from the articular cartilage is quite challenging due to a low cell content, the cross-linked extracellular matrix and considerably high levels of RNA degradation [60]. From this perspective, less than one-third of the extractions yielded RNA of sufficient quality and quantity for the analysis. In addition, transcriptome analysis does not convey information about proteins and posttranslational modifications.

\section{Conclusions}

These data further support an important role for FRZB in the homeostasis of the joint, in particular in the articular cartilage-bone biomechanical unit. The molecular up-regulation of other antagonists of the WNT signalling cascade in the absence of $F r z b$ and the similar activation of the $\beta$-catenin mediated cascade also provide evidence for the important homeostatic potential of the joint. From the clinical perspective, this should encourage the search for compounds that stimulate tissue homeostasis. Further analyses and future studies should focus on fine mapping of the interactions between WNTs, their receptors and antagonists, as well as modulating effects of the inhibitors on their own. These investigations appear necessary to better understand the complex biology of WNTs and SFRPs in the joint, thereby, more precisely defining therapeutic targets and strategies. Again, from the clinical perspective, our study suggests that WNT pathway modulators should be carefully selected and linked to specific activation or inhibition of intracellular cascades in order to predict their potential effects and toxicity.

\section{Additional material}

Additional file 1: Compiled list of WNT target genes based on the WNT Homepage.

Additional file 2: Complete list of all regulated genes and fold differences

Additional file 3: Associations of the differentially regulated gene set using databases defining "biological processes" as analyzed by PANTHER

Additional file 4: DAVID analysis of differentially expressed genes by pathway.

Additional file 5: GSEA analysis of all expressed genes by KEGG pathway.

\section{Abbreviations}

Acta2: actin, alpha 2, smooth muscle, aorta; BMP: bone morphogenetic protein; CamKIl: calcium/calmodulin-dependent protein kinase II; c-myc: vmyc myelocytomatosis viral oncogene homolog (avian); Col2a1/3a1/5a1/5a3: collagen type 2a1/3a1/5a1/5a3; DAVID: database for annotation:

visualization and integrated discovery; DKK: dickkopf; DMEM: Dulbecco's modified Eagle's medium; DNAsel: deoxyribonuclease; DPBS: Dulbecco's phosphate buffered saline; ECM: extracellular matrix; FDR: false discovery rate; FRZB: frizzled-related protein; GAGs: glycosaminoglycans; GAPDH: glyceraldehyde-3-phosphate dehydrogenase; GSEA: gene set enrichment analysis; HPRT: hypoxanthine guanine phosphoribosyl transferase; KEGG: Kyoto encyclopedia of genes and genomes; LEF: lymphoid enhancer factor; LRP5/6: low-density lipoprotein receptor-related protein 5/6; MAS: microarray analysis suite; MES: 2-(N-morpholino)ethanesulfonic acid; Nfatc2/4: nuclear factor of activated T-cells: cytoplasmic: calcineurin-dependent 2/4; OA: osteoarthritis; OD: optical density; PANTHER: protein analysis through evolutionary relationships; P-SMAD: phosphorylated-mothers against decapentaplegic homolog; PVDF: polyvinylidene difluoride; RE: responsive element; RMA: robust multiarray averaging; Rspo2: R-spondin 2; RT-PCR: realtime polymerase chain reaction; SDS: sodium dodecyl sulphate; SFRP: secreted frizzled-related protein; Sox17: SRY-box containing gene 14; Tbl1x: transducin (beta)-like 1X-linked; TBS: Tris-buffered saline; TCF: T cell factor; TGFß: transforming growth factor: beta; Wisp2: WNT1 inducible signaling pathway protein 1; WNT: wingless-type MMTV integration site family member

\section{Acknowledgements}

The authors would like to thank Jenny Peeters, Ann Hens and Lies Storms for managing the animal facility and providing technical support for the experiments. This work was supported by grants from the Flanders Research Foundation (FWO Vlaanderen - grant nr. G.0717.09), a GOA grant "signaling centers in joint development and disease" from the KU Leuven and a European Commission framework 7 program grant nr. 200800 "TREAT-OA". L. $\mathrm{L}$. is the recipient of a fellowship from the Institute for Science and Technology (IWT).

\section{Author details}

'Laboratory for Skeletal Development and Joint Disorders, Department of Development and Regeneration, KU Leuven, Belgium. ²Division of Rheumatology, University Hospitals Leuven, Belgium.

\section{Authors' contributions}

LL carried out all the experiments except for the experiments with ATDC5 cells. Experiments with ATDC5 cells were performed by ST and FC. Analysis of the micro-array data was performed by RL and LL. Manuscript preparation was carried out by $L L, R L$ and FC. All other authors were involved in the design of the study, interpretation of the data and revision of the manuscript. All authors read and approved the final manuscript.

\section{Competing interests}

The authors declare that they have no competing interests.

Received: 5 August 2011 Revised: 1 December 2011

Accepted: 20 January 2012 Published: 20 January 2012

\section{References}

1. Lories RJ: Joint homeostasis, restoration, and remodeling in osteoarthritis. Best Pract Res Clin Rheumatol 2008, 22:209-220.

2. Lories RJ, Luyten FP: The bone-cartilage unit in osteoarthritis. Nat Rev Rheumatol 2011, 7:43-49.

3. Lodewyckx L, Lories RJ: WNT signaling in osteoarthritis and osteoporosis: what is the biological significance for the clinician? Curr Rheumatol Rep 2009, 11:23-30.

4. Blom $A B$, van Lent $P L$, van der Kraan PM, van den Berg WB: To seek shelter from the WNT in osteoarthritis? WNT-signaling as a target for osteoarthritis therapy. Curr Drug Targets 2010, 11:620-629.

5. MacDonald BT, Tamai K, He X: Wnt/beta-catenin signaling: components, mechanisms, and diseases. Dev Cell 2009, 17:9-26.

6. Tu X, Joeng KS, Nakayama Kl, Nakayama K, Rajagopal J, Carroll TJ, McMahon AP, Long F: Noncanonical Wnt signaling through G protein- 
linked PKCdelta activation promotes bone formation. Dev Cell 2007, 12:113-127.

7. Lories RJ, Peeters J, Bakker A, Tylzanowski P, Derese I, Schrooten J, Thomas JT, Luyten FP: Articular cartilage and biomechanical properties of the long bones in Frzb-knockout mice. Arthritis Rheum 2007, 56:4095-4103.

8. Zhu M, Chen M, Zuscik M, Wu Q, Wang YJ, Rosier RN, O'Keefe RJ, Chen D: Inhibition of beta-catenin signaling in articular chondrocytes results in articular cartilage destruction. Arthritis Rheum 2008, 58:2053-2064.

9. Zhu M, Tang D, Wu Q, Hao S, Chen M, Xie C, Rosier RN, O'Keefe RJ, Zuscik M, Chen D: Activation of beta-catenin signaling in articular chondrocytes leads to osteoarthritis-like phenotype in adult betacatenin conditional activation mice. J Bone Miner Res 2009, 24:12-21.

10. Dell'Accio F, De Bari C, Eltawil NM, Vanhummelen P, Pitzalis C: Identification of the molecular response of articular cartilage to injury, by microarray screening: Wnt-16 expression and signaling after injury and in osteoarthritis. Arthritis Rheum 2008, 58:1410-1421.

11. Weng LH, Wang CJ, Ko JY, Sun YC, Wang FS: Control of Dkk-1 ameliorates chondrocyte apoptosis, cartilage destruction, and subchondral bone deterioration in osteoarthritic knees. Arthritis Rheum 2010, 62:1393-1402.

12. Dell'Accio F, De Bari C, El Tawil NM, Barone F, Mitsiadis TA, O'Dowd J, Pitzalis C: Activation of WNT and BMP signaling in adult human articular cartilage following mechanical injury. Arthritis Res Ther 2006, 8:R139.

13. Lane NE, Nevitt MC, Lui LY, de Leon P, Corr M: Wnt signaling antagonists are potential prognostic biomarkers for the progression of radiographic hip osteoarthritis in elderly Caucasian women. Arthritis Rheum 2007, 56:3319-3325.

14. Guo X, Day TF, Jiang X, Garrett-Beal L, Topol L, Yang Y: Wnt/beta-catenin signaling is sufficient and necessary for synovial joint formation. Genes Dev 2004, 18:2404-2417.

15. Day TF, Guo X, Garrett-Beal L, Yang Y: Wnt/beta-catenin signaling in mesenchymal progenitors controls osteoblast and chondrocyte differentiation during vertebrate skeletogenesis. Dev Cell 2005, 8:739-750.

16. Dell'Accio F, De Bari C, Luyten FP: Molecular markers predictive of the capacity of expanded human articular chondrocytes to form stable cartilage in vivo. Arthritis Rheum 2001, 44:1608-1619.

17. Hoang B, Moos M Jr, Vukicevic S, Luyten FP: Primary structure and tissue distribution of FRZB, a novel protein related to Drosophila frizzled, suggest a role in skeletal morphogenesis. J Biol Chem 1996, 271:26131-26137.

18. Enomoto-Iwamoto M, Kitagaki J, Koyama E, Tamamura Y, Wu C, Kanatani N, Koike T, Okada H, Komori T, Yoneda T, Church V, Francis-West PH, Kurisu K, Nohno T, Pacifici M, Iwamoto M: The Wnt antagonist Frzb-1 regulates chondrocyte maturation and long bone development during limb skeletogenesis. Dev Biol 2002, 251:142-156.

19. Nucleomics Core: A VIB Facility. Microarrays, nCounter, next-gen sequencing \& bioinformatics. [http://www.microarray.be].

20. Gene Expression Omnibus (GEO). [http://www.ncbi.n/m.nih.gov/geo/]

21. ImageJ: Image Processing and Analysis in Java. NIH Image, National Institute of Health. [http://rsbweb.nih.gov/ij/].

22. Giulietti A, Overbergh L, Valckx D, Decallonne B, Bouillon R, Mathieu C: An overview of real-time quantitative PCR: applications to quantify cytokine gene expression. Methods 2001, 25:386-401.

23. Gosset M, Berenbaum F, Thirion S, Jacques C: Primary culture and phenotyping of murine chondrocytes. Nat Protoc 2008, 3:1253-1260.

24. Bioconductor software. [http://www.bioconductor.org].

25. PANTHER Classification System. [http://www.pantherdb.org].

26. DAVID Bioinformatics Resources 6.7. [http://david.abcc.ncifcrf.gov/].

27. GSEA Gene Set Enrichment Analysis homepage. [http://www. broadinstitute.org/gsea].

28. Huang DW, Sherman BT, Lempicki RA: Systematic and integrative analysis of large gene lists using DAVID bioinformatics resources. Nat Protoc 2009, 4:44-57.

29. Huang DW, Sherman BT, Lempicki RA: Bioinformatics enrichment tools: paths toward the comprehensive functional analysis of large gene lists. Nucleic Acids Res 2009, 37:1-13.

30. Mi H, Dong Q, Muruganujan A, Gaudet P, Lewis S, Thomas PD: PANTHER version 7: improved phylogenetic trees, orthologs and collaboration with the Gene Ontology Consortium. Nucleic Acids Res 2010, 38 : D204-D210.
31. Mootha VK, Lindgren CM, Eriksson KF, Subramanian A, Sihag S, Lehar J, Puigserver $\mathrm{P}$, Carlsson E, Ridderstrale M, Laurila E, Houstis N, Daly MJ, Patterson N, Mesirov JP, Golub TR, Tamayo P, Spiegelman B, Lander ES, Nirschhorn JN, Altshuler D, Groop LC: PGC-1alpha-responsive genes involved in oxidative phosphorylation are coordinately downregulated in human diabetes. Nat Genet 2003, 34:267-273.

32. Subramanian A, Tamayo P, Mootha VK, Mukherjee S, Ebert BL, Gillette MA, Paulovich A, Pomeroy SL, Golub TR, Lander ES, Mesirov JP: Gene set enrichment analysis: a knowledge-based approach for interpreting genome-wide expression profiles. Proc Natl Acad Sci USA 2005, 102:15545-15550.

33. Thomas PD, Campbell MJ, Kejariwal A, Mi H, Karlak B, Daverman R, Diemer K, Muruganujan A, Narechania A: PANTHER: a library of protein families and subfamilies indexed by function. Genome Res 2003, 13:2129-2141.

34. KEGG PATHWAY database. [http://www.genome.jp/kegg/pathway.html].

35. Biocarta homepage. [http://www.biocarta.com].

36. WNT homepage. [http:/NNT. stanford.edu].

37. Heinemeyer T, Wingender E, Reuter I, Hermjakob H, Kel AE, Kel OV, Ignatieva EV, Ananko EA, Podkolodnaya OA, Kolpakov FA, Podkolodny NL, Kolchanov NA: Databases on transcriptional regulation: TRANSFAC, TRRD and COMPEL. Nucleic Acids Res 1998, 26:362-367.

38. Matys V, Kel-Margoulis OV, Fricke E, Liebich I, Land S, Barre-Dirrie A, Reuter I, Chekmenev D, Krull M, Hornischer K, Voss N, Stegmaier P, LewickiPotapov B, Saxel H, Kel AE, Wingender E: TRANSFAC and its module TRANSCompel: transcriptional gene regulation in eukaryotes. Nucleic Acids Res 2006, 34:D108-D110.

39. Jho EH, Zhang T, Domon C, Joo CK, Freund JN, Costantini F: Wnt/betacatenin/Tcf signaling induces the transcription of Axin2, a negative regulator of the signaling pathway. Mol Cell Biol 2002, 22:1172-1183.

40. Hoekstra M, van der Lans CA, Halvorsen B, Gullestad L, Kuiper J, Aukrust P, van Berkel TJ, Biessen EA: The peripheral blood mononuclear cell microRNA signature of coronary artery disease. Biochem Biophys Res Commun 2010, 394:792-797.

41. Takahashi H, Sakuta H, Shintani T, Noda M: Functional mode of FoxD1/ CBF2 for the establishment of temporal retinal specificity in the developing chick retina. Dev Biol 2009, 331:300-310.

42. Wu Z, Zheng S, Li Z, Tan J, Yu Q: E2F1 suppresses Wnt/beta-catenin activity through transactivation of beta-catenin interacting protein ICAT. Oncogene 2011, 30:3979-3984.

43. Evangelou E, Chapman K, Meulenbelt I, Karassa FB, Loughlin J, Carr A, Doherty M, Doherty S, Gomez-Reino JJ, Gonzalez A, Halldorsson BV, Hauksson VB, Hofman A, Hart DJ, Ikegawa S, Ingvarsson T, Jiang Q, Jonsdottir I, Jonsson H, Kerkhof HJ, Kloppenburg M, Lane NE, Li J, Lories RJ, van Meurs JB, Näkki A, Nevitt MC, Rodriguez-Lopez J, Shi D, Slagboom PE, et al: Large-scale analysis of association between GDF5 and FRZB variants and osteoarthritis of the hip, knee, and hand. Arthritis Rheum 2009, 60:1710-1721.

44. Bovolenta P, Esteve P, Ruiz JM, Cisneros E, Lopez-Rios J: Beyond Wnt inhibition: new functions of secreted Frizzled-related proteins in development and disease. J Cell Sci 2008, 121:737-746.

45. Nalesso G, Sherwood J, Bertrand J, Pap T, Ramachandran M, De Bari C, Pitzalis C, Dell'Accio F: WNT-3A modulates articular chondrocyte phenotype by activating both canonical and noncanonical pathways. J Cell Biol 2011, 193:551-564.

46. Wu JJ, Weis MA, Kim LS, Eyre DR: Type III collagen, a fibril network modifier in articular cartilage. J Biol Chem 2010, 285:18537-18544.

47. Wu JJ, Weis MA, Kim LS, Carter BG, Eyre DR: Differences in chain usage and cross-linking specificities of cartilage type $\mathrm{V} / \mathrm{XI}$ collagen isoforms with age and tissue. J Biol Chem 2009, 284:5539-5545.

48. Wotton SF, Duance VC: Type III collagen in normal human articular cartilage. Histochem J 1994, 26:412-416.

49. Young RD, Lawrence PA, Duance VC, Aigner T, Monaghan P: Immunolocalization of collagen types II and III in single fibrils of human articular cartilage. J Histochem Cytochem 2000, 48:423-432.

50. Kiani C, Chen L, Wu YJ, Yee AJ, Yang BB: Structure and function of aggrecan. Cell Res 2002, 12:19-32.

51. Kahai S, Vary CP, Gao Y, Seth A: Collagen, type V, alpha1 (COL5A1) is regulated by TGF-beta in osteoblasts. Matrix Biol 2004, 23:445-455. 
52. Bonaventure J, Zylberberg L, Cohen-Solal L, Allain JC, Lasselin C, Maroteaux P: A new lethal brittle bone syndrome with increased amount of type V collagen in a patient. Am J Med Genet 1989, 33:299-310.

53. Bateman JF, Chan D, Mascara T, Rogers JG, Cole WG: Collagen defects in lethal perinatal osteogenesis imperfecta. Biochem J 1986, 240:699-708,

54. Herbage D, Borsali F, Buffevant C, Flandin F, Aguercif M: Composition, cross-linking and thermal stability of bone and skin collagens in patients with osteogenesis imperfecta. Metab Bone Dis Relat Res 1982, 4:95-101.

55. Jones CJ, Cummings C, Ball J, Beighton P: Collagen defect of bone in osteogenesis imperfecta (Type I). An electron microscopic study. Clin Orthop Relat Res 1984, 208-214.

56. Muller PK, Raisch K, Matzen K, Gay S: Presence of type III collagen in bone from a patient with osteogenesis imperfecta. Eur J Pediatr 1977, 125:29-37.

57. Pope FM, Nicholls AC, Eggleton C, Narcissi P, Hey EN, Parkin JM: Osteogenesis imperfecta (lethal) bones contain types III and V collagens. J Clin Pathol 1980, 33:534-538.

58. Mahmoudi T, Boj SF, Hatzis P, Li VS, Taouatas N, Vries RG, Teunissen H, Begthel H, Korving J, Mohammed S, Heck AJ, Clevers H: The leukemiaassociated Mllt10/Af10-Dot1l are Tcf4/beta-catenin coactivators essential for intestinal homeostasis. PLoS Biol 2010, 8:e1000539.

59. Davidson $G$, Niehrs $C$ : Emerging links between CDK cell cycle regulators and Wnt signaling. Trends Cell Biol 2010, 20:453-460.

60. Ruettger A, Neumann S, Wiederanders B, Huber R: Comparison of different methods for preparation and characterization of total RNA from cartilage samples to uncover osteoarthritis in vivo. BMC Res Notes 2010, $3: 7$

doi:10.1186/ar3695

Cite this article as: Lodewyckx et al:: Tight regulation of wingless-type signaling in the articular cartilage - subchondral bone biomechanical unit: transcriptomics in Frzb-knockout mice. Arthritis Research \& Therapy 2012 14:R16.

\section{Submit your next manuscript to BioMed Central} and take full advantage of:

- Convenient online submission

- Thorough peer review

- No space constraints or color figure charges

- Immediate publication on acceptance

- Inclusion in PubMed, CAS, Scopus and Google Scholar

- Research which is freely available for redistribution

Submit your manuscript at www.biomedcentral.com/submit 